\title{
LAS MONEDAS CON NOMBRES DE ÉTNICOS DEL S. II a.C. EN EL NORDESTE PENINSULAR. ¿REFLEJO DE POSIBLES CIRCUNSCRIPCIONES?, ¿CIVITATES CON DOBLE NOMBRE?
}

\author{
POR \\ ARTURO PÉREZ ALMOGUERA \\ Universidad de Lleida
}

\section{RESUMEN}

En el s. II a.C. se emiten en el nordeste de Hispania monedas con el nombre de étnicos conocidos por las fuentes escritas. Se plantea el problema de si responden a una organización territorial en circunscripciones que, curiosamente, corresponden con las regiones y principales populi que cita Plinio. Por otro lado estas cecas podrían corresponder a localidades que pudieran tener otro nombre.

\section{SUMMARY}

In the 2 nd century $\mathrm{BC}$ coins were being minted in the northeast of Hispania with ethnic names known by written sources. This raises the problem of whether they are dependent upon a territorial organisation in districts that, interestingly, would be the regiones and major populi mentioned by Pliny in the $1^{\text {st }}$ Century. On the other hand, these mints might correspond to places with their own city name.

PALABRAS CLAVE: Hispania citerior. República. Numismática. Organización territorial. Regiones.

KEY WORDS: Hispania citerior. Roman Republic. Numismatics. Territorial Organisation. Regiones.

\section{INTRODUCCIÓN}

Nuestro conocimiento de la etapa que media entre la pacificación de Catón a inicios del s. II a.C. ${ }^{1}$ y la comprobada fundación o refundación de ciudades a fines del mismo y sobre todo a inicios del siguiente en el nordeste peninsular es muy escaso. Roma se ha asentado en la zona y las fuentes escritas se orientan hacia el interior aún no domeñado, no ofreciendo prácticamente información sobre las consecuencias de la asunción de la conquista a partir de la realidad con que se encontraron. Creo que lo que podamos suponer que ocurrió se derivará sobre todo

\footnotetext{
${ }^{1}$ A partir de ahora, salvo que se indique lo contrario, las fechas han de entenderse a.C.
}

a través de la numismática, tan prolífica en la zona en esta etapa y, en concreto, la que en sus leyendas podemos reconocer como nombres de populi atestiguados por fuentes anteriores o posteriores, hecho casi insólito en otras zonas peninsulares. No pretendo ni mucho menos realizar un estudio numismático, sino basarme en los datos de los especialistas en ese campo con el fin de intentar pergeñar a través de sus datos la posible huella de una primera organización propiciada por los conquistadores.

Se ha incidido en muchas ocasiones que, en la Hispania republicana, las monedas con caracteres indígenas son el único documento propio que nos han dejado las ciudades, o, si queremos, las sociedades poliadas o estados, dado el valor polisémico del término ciudad. El resto de la información a este respecto es la escasa que proporcionan las fuentes escritas clásicas y, aún menor, las epigráficas, en cualquier caso pocas veces indígena. La singularidad que ofrecían las emisiones del nordeste peninsular, básicamente en Cataluña, que abarcaban desde fines del s. III hasta, quizás, antes del meridiano del I, es manifiesta en cuanto al alto número de cecas y características incluida una cierta uniformidad, en contraposición a lo que ocurría en otras zonas, hasta el punto que se ha planteado si, a excepción de los indiketes, podemos hablar con propiedad de pueblos ibéricos al norte del Ebro (García-Bellido 1998) que, eso si, utilizaron la ibérica quizás como lingua franca en sus documentos epigráficos. De las cecas catalanas me ocupé hace ya más de una década (Pérez Almoguera 1996) con el fin de intentar vislumbrar a través de ellas los indicios de posibles organizaciones territoriales que Roma llevó a cabo durante tan dilatado periodo de tiempo, a pesar de la carencia de horizontes estratigráficos claros que permitieran afinar las posibles cronologías, problema que continua por desgracia vigente. Vuelvo a ocuparme del tema 
centrándome en un aspecto que apenas traté en la ocasión anterior, pues si bien me ocupé de la organización del s. II en que tiene lugar la multiplicación de cecas, no incidí lo suficiente en lo que pudieran representar las que llevan nombres de étnicos, de populi (llamados sólo por Livio en ocasiones gentes; Rodríguez 1996, 63) conocidos por las fuentes escritas, frente a las que lo hacen claramente de ciudades. Sobre ellas trataré aquí.

La mencionada uniformidad de las emisiones ibéricas ha hecho pensar en «una sugerencia por parte de la administración romana» (Ripollés 2005, 198) cuando no en una imposición que estimula las iconografías y grafías indígenas, aunque también se hayan supuesto, y no pocas veces, como resultado de una decisión propia de las diversas ciudades. Por mi parte creo posible que reflejen la primera organización realizada por Roma tras la asunción de la conquista, bien con la pacificación de Catón que significaría un cambio importante en la implantación territorial o quizás tras la de Tiberio Sempronio Graco de otros territorios al oeste (Campo 1998, 40), pero en cualquier caso antes de 154 (García-Bellido 1993b, 104) teniendo en cuenta la aparición del denario ibérico, aunque se han propuesto fechas incluso posteriores, en torno a 133 (recientemente, de nuevo, López Sánchez 2005, 511), datación excesivamente tardía a nuestro entender aún cuando es posible que sea entonces cuando se multipliquen las cecas con la aparición de nuevas. Quizás antes del meridiano de siglo sería una fecha adecuada si estas amonedaciones las relacionamos con la presencia de un aparato fiscal romano no existente con anterioridad de forma regular al menos antes de 171 pero sí ya en 133 . El problema es que no siempre resulta claro que las acuñaciones fueran para satisfacer una función fiscal, sobre todo si se tiene en cuenta la abundancia de bronce -que no responde a una lógica fiscal ni es codiciado como botín de guerra- sobre la plata (Ñaco 1999; Aguilar-Ñaco 1997; Ñaco-Prieto 1999) que sí podría servir para ese fin y que es acuñada por pocas cecas. Además tanto para las emisiones de plata como para las de bronce se ha venido defendiendo el uso de módulos que es posible que en realidad respondan a una tradición indígena (García-Bellido 2001), incluso premonetaria, con lo cual la cronología de las monedas ya no dependería de tipos romanos, como es el caso discutido de la aparición del denario. No está de más recordar que los iberos conocían la moneda - o la economía monetaria- antes de acuñar, por sus contactos y comercio con los griegos.

En su mayor parte se trata de cecas que no habían emitido con anterioridad ni dracmas ni divisores. Tan solo perviven tres de las que lo habían hecho: iltiŕta, iltirke y kese y solo las dos últimas ostentan nombre relacionado con populi, iltiŕke con los ilergetes o con los ilercaones y kese con los cesetanos. Junto a estas y a otras con nombres de ciudades, aparecen en el s. II también en Cataluña, y en genitivo, las cecas de auśesken, laieśken y untikesken que claramente nos remiten a ausetanos, layetanos e indiketes. Iltiŕke utilizará ahora también el genitivo (iltiŕkesken). Más al oeste, sedeisken se refiere de forma clara a los sedetanos, y quizás, aunque más discutible, sesars y baŕśkunes pueden hacerlo asimismo a suesetanos y vascones. De hecho se trata de los populi de cierta entidad que mencionan las fuentes escritas y, además, coinciden con las regiones y pueblos que dos siglos después nos aparecen en la descripción del nordeste de Hispania de Plinio. La pregunta inmediata es si ello significa que reflejaban una organización basada en las realidades étnicas que, evidentemente en época de Plinio ya no tenían vigencia, pero pervivía el recuerdo de que la tuvieron en un momento. Tan sólo notamos a faltar dos pueblos de Cataluña, cerretani y lacetani, que plantean problemas que trataremos más adelante, como haremos también con el de los iacetani más al oeste. No entraré en el problema sobre lo que se esconde tras los nombres de etnias que mencionan las fuentes y nuestra ignorancia sobre la percepción que de ellas tendrían los indígenas incluidos en las mismas por griegos y romanos (Grau $2005,108)$ pues lo seguro es que las diversas etnias nunca habían constituido estados unificados, contando cada una con diversas ciudades independientes aunque es posible que se crearan a partir de un ethnos tribal, ya desde el s. vi, que solo volverían a unirse en especiales casos de guerra bajo la dirección de caudillos o reyezuelos con aptitudes militares (Gracia 2006, 37). Aunque correspondieran sólo a una realidad percibida por los conquistadores y no tan claramente por los indígenas en todos los casos, nos interesa que Roma las consideró en alguna medida para sus intereses y las monedas de que tratamos serían un indicio de ello. Frente a lo que ocurre para los estudiosos de la génesis y evolución de los pueblos prerromanos, el que las fuentes sean generalmente tardías, inmediatamente anteriores, contemporáneas o posteriores a la Segunda Guerra Púnica, benefician nuestro propósito.

Como hemos visto, las de Cataluña y la inmediata aragonesa de los sedetanos, es decir las del área ibérica, a excepción de la de los cesetanos, tienen la característica de presentar la lectura en genitivo ibérico -sken. La cuestión básica era si se trataba de 


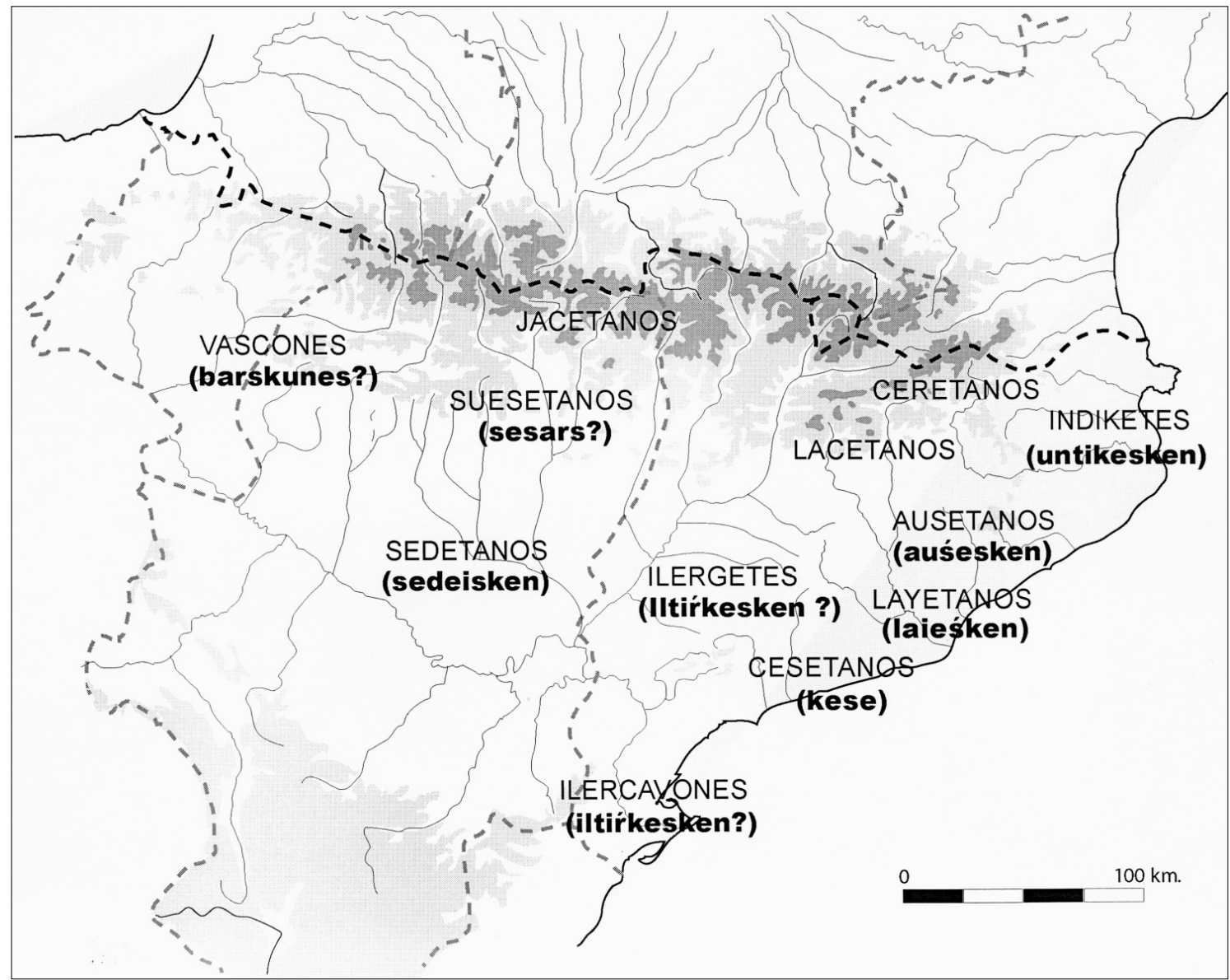

Fig. 1. Los pueblos del nordeste peninsular y las correspondientes cecas relacionadas con su nombre.

monedas «tribales» o correspondían a una ciudad. Aunque se ha pretendido que corresponderían a pueblos, mi opinión es que se trata de emisiones ciudadanas pues no hay ejemplos claros en el mundo de la Antigüedad en sentido contrario y, por otro lado, el populus suele tener una ciudad-cabecera que ostenta un nombre relacionado con el mismo (Abascal-Espinosa 1989, 17). La discusión es dilucidar si con anterioridad a la etnia un grupo da nombre a la ciudad o si la etnia aparece unida al surgimiento del estado como conciencia de grupo (Burillo 1996, 112). Creo que la ciudad es la que había dado en un momento dado nombre al populus y no viceversa como sería el caso de kese en nominativo. Al menos en lo que se refiere a auśesken hay cierto consenso en que se trata de una ciudad (Untermann 1992, 25) y el mismo caso sería al de sedeisken (Beltrán 1996, 31). ¿Eran continuadoras de otra ceca?, o mejor, ¿tenían algunas ciudades doble nom- bre, uno propio y otro relacionado con el populus del que en algún modo venían a ser su cabecera? Es posible que Roma considerara oportuno que, en una suerte de capitalidad o no pero relacionada con una organización territorial ostentara el nombre del étnico sin que sea preciso suponer una contributio, es decir que se tratara de un núcleo nuevo formado por la instalación en el mismo de diversos núcleos menores anteriores, como ocurre en fundaciones posteriores, aunque también republicanas, que ostentan nombre indígena (Abad-Bendala 1995, 17-18). De hecho no esta claro cual fue el fin que pretendió Roma con estas cecas. Procede recordar aquí lo que F. Burillo $(1998,215)$ proponía para los celtíberos que, evidentemente, no participaron de la organización a que nos referimos: la etnia no llegó a imponerse a la ciudad políticamente, pero subyace como realidad social y puede emerger en momentos políticos determinados. 


\section{LOS PRECEDENTES. DRACMAS Y DIVISORES}

Si prescindimos de las dracmas y divisores ortodoxamente helenos de Emporion y Rhode, las llamadas dracmas ibéricas son las más antiguas monedas del nordeste peninsular, mejor conocidas en los últimos años tras la publicación de la monografía de L. Villaronga y la revisión de su ya clásica obra de 1979 (Villaronga 1998; Id. 2004, 110-111). Es bien sabido que lastran su estudio, no hay que olvidarlo a la hora de establecer conclusiones, la escasez de estas monedas que suman menos de 800 ejemplares en total. El hecho es que siguen apareciendo nuevas, aunque con cuentagotas, que incluso nos informan de cecas desconocidas hasta entonces - el caso notable de $k u Y$ documentada con cinco dracmas y troqueles o cuños de plomo en Tivissa, posible ubicación de una ceca (Tarradell 2003/2004) — , y no hay motivo para pensar que no aparezcan más.

Por su lectura, algunas pueden identificarse con localidades antiguas conocidas, otras no tanto y otras es prácticamente imposible, pero con todo, parecen circunscribirse a la actual Cataluña. Con dudas serias, tan sólo una ceca se ubicaría en Aragón, belsa, belsekuai o belseśalir, recientemente conocida, de la que contamos con 7 ejemplares, que en opinión de Villaronga $(1998,63)$ pudiera ser la posterior colonia de Celsa, pero ello no es por otra parte seguro. Las atribuciones a cecas fuera del nordeste, a excepción de los casos singulares de arse, con seguridad anterior a las que tratamos, y de śaitabi, son dudosas. Su área de emisión coincide con el mismo territorio que acuñará posteriormente denarios y bronces ibéricos, a excepción de una extensión del valle medio del Ebro en su orilla izquierda que no había acuñado previamente. Por tanto considero que, con todas sus limitaciones y la prudencia necesarias, comparar estas primeras emisiones con las posteriores a la actuación de Catón - momento que creo de asunción de la conquista - nos darán un indicio de cómo actuó Roma por vez primera sobre la realidad que encontraron en el nordeste a su llegada, pues además del breve periodo de acuñación atribuido a dracmas y divisores - fines del s. III y años inmediatos a pesar de la ausencia de estratigrafías precisas- son contemporáneas, o casi, de los primeros tiempos de presencia romana en la península. No hay ninguna ceca ibérica al norte del Ebro datable con seguridad antes de la Segunda Guerra Púnica, aunque veremos que se ha propuesto que taŕakon lo hizo antes (en contra Villaronga 1994b, 19). De hecho fue precisamente la guerra lo que hizo aumentar el volumen de plata acuñada por las necesidades de los ejércitos conten- dientes (García-Bellido - Ripollés 1998) y en Cataluña había al menos menas de plata en el Priorat, Pirineo y Prepirineo explotadas ya desde siglos antes (Rafel et al. prensa). En cualquier caso, en los tesoros de Ullastret y del Turó de Montgrós, fechado a inicios de la contienda, no había dracmas ibéricas, sólo de Emporion (Campo 1998, 31).

Así, las llamadas dracmas ibéricas constituyen un reflejo de las realidades poliadas con que se encontraron los conquistadores y se suele convenir que fueron éstos los que propiciaron, si no impusieron, las acuñaciones, aunque se ha propuesto la posibilidad de que pudieran haber sido los propios indígenas que estaban contra Roma los que lo hicieron (De Guadán 1956, 116; Villaronga 1998, 99). Es cierto que podía argüirse como argumento a favor que la principal ceca de entonces por el número de emisiones, iltiŕta, la posterior Ilerda, era la ciudad cabecera de los ilergetes, el pueblo que sólo o en coalición con otros vecinos se distinguió por su tenaz oposición a Roma sin parangón con otros del nordeste. Si hubiera que deducir por la mayor o menor cantidad de monedas la importancia de una ciudad, habría que convenir que esta última ceca, con 66 ejemplares de dracmas —con leyenda iltiŕtar, iltiŕtaśalir, iltiŕtalirustin o iltiŕtasalirnai- y 21 de divisores - con leyenda tiŕta, iltiŕrta o iltita- (Villaronga 1994a, 41, núms. 32 a 39; 43, núms. 46-47; 44 núms. 50 A, 53; 514 , núm. 50 B), era la más importante a fines del s. III y, además, junto a kese y a un ejemplar de sikara, la única que habría emitido divisores. Creo que incluso estas monedas debieron ser consecuencia de imposiciones romanas (Pérez Almoguera 1993-1994), como pudiera deducirse cuando Livio, aparte de las referencias a los hispanos en general impelidos por P. y Gn. Escipión a la satisfacción de numerario para pagar a su ejército $(23,48,4)$, indica que , ya en 218 , los ilergetes hubieron de pagar dinero tras una operación de castigo $(21,22,8)$, y en 206 se le exigió a Mandonio lo mismo, y de nuevo al año siguiente, junto a vestuario y alimentos, una vez muerto Indíbil $(21,29,35)$. Apiano por su parte (Iber. 37) repite la imposición de un tributo a Indíbil, pero también en 211 Asdrúbal exigió dinero al mismo. E. García Riaza (2002, 15-16) hace hincapié en que ya en 218 se les exige pecunia, lo que no sucede con otros pueblos que han de pagar bienes, y aunque no se puede desechar que no contaran con ceca propia y los pagos pudieran hacerse en metal en bruto, la abundancia citada de iltiŕta frente a otras cecas nos mueve a pensar que sí.

Además de iltiŕta, en las dracmas ibéricas otros topónimos son identificables, como taŕakon-kese o 
baŕkeno, otros son de identificación dudosa como iltirke, otros son desconocidos, otros corresponden a antropónimos —caso de olośoŕtin (De Hoz 1995), aunque hay quien lo considera topónimo (Villaronga 2004, 110)—, y finalmente otras monedas ostentan simplemente una mala imitación de la leyenda griega Emporion o ilegibles - las llamadas pseudoibéricas-, o simplemente anepígrafas. Como fuere, que aludan a étnicos conocidos por las fuentes, de todas ellas sólo dos permiten hacerlo: kese e iltiŕke.

\section{EL S. II. LA ASUNCIÓN DE LA CONQUISTA. LAS CECAS, ¿NUEVAS O SUCESORAS DE OTRAS?}

Junto a las ya documentadas antes, iltiŕta, iltiŕkesken y kese, aparecen en el s. II, como indicaba, nuevas cecas que significaron un cambio considerable con respecto a la realidad anterior. Como se observa y ya se ha visto, las que ostentan nombre étnico menos kese y las más orientales sesars y baŕśkunes en el límite o fuera del área ibérica, aparecen con el sufijo -(e)sken, el genitivo ibérico exclusivo de leyendas monetales (De Hoz 2002), de la misma manera que aparecen también en el mismo caso, en griego naturalmente, las de Emporion y Rhode, y en latín, algunas de la propia Roma, si bien en este caso no es lo normal. Se ha sostenido que no está por lo demás claro si se trata de un sufijo que forma étnicos o localicios o sólo indica funciones específicas de un topónimo (Luján 2005). En realidad el genitivo sería - en, propio de los antropónimos, y la $-k$ sería un polarizador, siendo quizás -ken el genitivo de los tribónimos (Rodríguez Ramos 2005, 28-29).

En lo que hace a kese, el que aparezca en nominativo puede explicarse por ser las continuadoras de las anteriores dracmas y divisores que ya aparecían en el mismo caso además, quizás, del carácter singular de Tarraco como base principal romana de la citerior, mientras en lo que se refiere a las orientales sesars y baŕśkunes, se trata de un caso diferente por no ser la lengua ibérica la reflejada en ellas.

A menudo se ha señalado que el hecho de aparecer el nombre de la ceca en genitivo indicaba su condición de monedas tribales, a lo que siempre hemos propuesto que son ciudadanas y tras ellas hay una localidad emisora que en algunos casos podía tener doble nombre. Que no es algo exclusivo de las que ostentan nombres de populi lo muestra la utilización en cecas que no se discute su atribución ciudadana, como otobeśken, arsesken, ikalesken, o ur- kesken, si bien ninguna con seguridad se encontraría en el área que estudiamos pues son ciudades edetanas, contestanas o bastetanas. Para otobeśken, no obstante, se ha propuesto la ubicación posible en Cataluña o Aragón aunque también se ha hecho en la zona edetana. El hecho de ser la única que no corresponde a un étnico nos mueve a pensar su no adscripción a nuestra zona, aunque desde luego no es seguro. Además la cronología de su única emisión es muy posterior a las que tratamos.

Recalquemos que todas las que se emiten en el área catalana e inmediata aragonesa en genitivo, son en su totalidad con un nombre que coincide con los etnónimos conocidos por las fuentes y lo hacen en el s. II. En ella, las ciudades con nombre no relacionado con étnico lo hacen siempre en nominativo. El por qué del uso del genitivo no esta claro, pero permite suponer que todas ellas debieron comenzar al unísono y formar parte de un mismo proyecto organizativo o recaudatorio. En cualquier caso no parece que sea algo casual. La interpretación de que quizás se deba a una tradición indígena (Beltrán 1993, 262) no parece clara. Bien es cierto, como hemos visto, que después de todo las dracmas y divisores de Emporion y Rhode tienen su leyenda en genitivo plural, pero también lo es que ello no ocurre en las dracmas ibéricas salvo que, único caso, la leyenda iltiŕkes fuera abreviación de iltiŕkesken, lo que no considero probable dado que también encontramos la lectura iltirkesalirban. Por lo tanto el genitivo étnico sería una novedad del s. II, aunque la dificultad es precisar en que momento concreto.

Las nuevas monedas nos hablan de una jerarquización en base a la emisión o no de plata. Las que lo hacen, y por ello serían auténticas capitales regionales, se reducen a iltirta, kese y, en menor medida auśesken. Al oeste también lo hicieron sesars, baŕśkunes, bolśkan y la quizás sedetana kelse —aunque según Ptolomeo era ilergete- pero sólo a partir de 133 constituyendo un caso diferente similar al de otra ceca suesetana o vascona como sekia, que también emitirá denarios. El que no lo haga untikesken se explica por hacerlo Emporion, después de todo la misma ciudad. Junto a ellas las otras cecas de la primera mitad y mediados Idel s. II — siempre con las dudas de si antes de mediados se emiten-, iltiŕkesken, laieśken y sedeisken, emitiran solo bronce como lo harán también otras cecas con nombres ciudadanos: aŕketuŕki, euśtibaikula, ilturo y la problemática lauro en Cataluña, en la primera mitad de siglo, y las mismas más ore, y, las más problemáticas, abariltur, masonsa — pudiera ser aragonesa- y ośkumken en la segunda. En Aragón y Navarra, emitirán bronces en 
la primera y segunda mitad de siglo arsaos, a mediados bolśkan y alaun, y en la segunda mitad iltukoite, ontikes, tiŕsos y uḿanbaate. De ellas no trataremos al no relacionarse su nombre con étnicos. Tampoco nos referiremos, salvo un caso preciso el de los jacetanos - y por el mismo motivo a las nuevas cecas que aparecen a fines de siglo o ya a inicios del I.

El fenómeno que nos interesa afectó sólo al área ibérica del nordeste y al área izquierda del Ebro medio, no dándose en los vecinos pueblos celtas donde por otra parte Plinio tampoco menciona regiones, y donde las únicas cecas que encontramos con posible nombre étnico son las de teitiakoś, titiakoś y titum (García-Bellido \& Blázquez 2001, 365-369) en algunas opiniones de los titos, del valle del Jalón, aunque ello no resulta claro: tanto la primera como la segunda se han considerado de los berones y quizás relacionada con Tritium Magallum —no las respectivas Tritium berona y várdula-, la primera emitiendo en el s. I, mientras la segunda lo haría en la segunda mitad del II. En cuanto a titum pudiera aludir, pero la fecha de sus escasas emisiones, fines del II e inicios del I, la diferencia claramente del momento que tratemos.

Analizaremos a continuación cada una de las cecas del nordeste con nombre étnico y los problemas que plantean individual y colectivamente.

\section{DE NUEVO LA DUALIDAD KESE-TAŔAKON}

kese es la única ceca con nombre de étnico que no aparece nunca en genitivo y, desde luego, por su acuñación en plata y la cantidad de su numerario una auténtica capital regional que emite desde el s. III al I a.C. Sólo en algunas ocasiones aparece con la forma keseku (-ku indica pertenencia u origen; Villaronga 2004, 111; Marqués de Faria 2001, 99). Al mismo tiempo nos encontramos ante el único caso en la zona que tratamos, fuera del especial untikeskenEmporion, que cuenta con un alto grado de aceptación de que se trata de una localidad con doble nombre, pues no sería sino Tarraco, la principal base romana de la citerior y futura capital provincial (entre otros, Beltrán 1984, 169; Keay 1996, 157; Otiña-Ruiz de Arbulo 2000; Roldán-Santos 1997, 11; Siles 1976, 23; Tovar 1989, C-570) que, con la leyenda taŕakon, emite dracmas a finales del s. III. El problema es que también se registran dracmas y más recientemente también divisores con leyenda kese que, razonablemente, creo, serían coetáneas o casi de las anteriores, lo que admite pensar en la posibilidad de dos localidades diferentes al menos en el s. III (GarcíaBellido-Blázquez 2001, 32, 240). Por otra parte, si la última fuera la Cissa o Cissis que mencionan respectivamente Polibio $(3,76,5)$ y Livio $(21,60,61)$ en sucesos alusivos al año 218 claramente diferenciándola de Tarraco, nos encontraríamos ante otro argumento para suponerlas dos localidades diferentes en esas fechas (Mayer-Rodà 1986; Alföldy 1991, 23), pero esta última no necesariamente ha de ser la misma que Cese a pesar de su parecido toponímico (Pou-Sanmartí-Santacana 1993, 183). Cissa o Cissis no se encontraba en la costa, aunque no muy alejada (Arrayás 2006, 31), y era además un oppidum parvum de escasa importancia como prueba su no mención en tiempos posteriores. Se ha propuesto su ubicación incluso lejos de Tarragona, en las leridanas Guissona e incluso Molí d’Espigol en Tornabous (Sanmartí-Santacana 2005, 34) dado que tras la batalla en ella acaecida fue capturado el régulo ilergete Andobales. En una interpretación extrema, se ha negado incluso su existencia suponiéndola una creación de fuentes posteriores - no olvidar las fechas en que escriben Polibio y aún más Livio-, una invención propagandística para adornar un momento no propicio a las tropas romanas quizás tras una batalla que se dio no lejos de Tarraco (Otiña-Ruiz de Arbulo 2000, 132).

Los partidarios de que taŕakon y kese fueron dos localidades diferentes han tratado de interpretar el hecho de que Cese, al ser tan insignificante, fue posteriormente absorbida por Tarraco (Alföldy 1991, 23), o bien que la última fue una fundación romana sobre una realidad anterior llamada Cese - o junto a ellacon la que acabaría por identificarse, por lo que en principio no sería sino una dipolis (Abad-Bendala $1995,17)$. Se trataría en todo caso de una unión temprana, como indica la acuñación de dracmas con ambos nombres (García-Bellido \& Blázquez 2001, 240).

La cuestión no es fácil de dirimir, pues por un lado Tarraco es un nombre tan ibérico como Cese (Alföldy 1991, 18), aunque se haya pensado que, aunque de origen griego, es latino (abundancia de topónimos de raíz tar- en el Mediterráneo; Otiña-Ruiz de Arbulo 2000, 132) y, por otro, las fuentes escritas parecen indicar que Tarraco existía con ese nombre en 218, con lo que estrictamente no sería, según la famosa cita de Plinio (n.h. 3, 21), una obra de los Escipiones más allá de un acondicionamiento como plaza fuerte romana y centro administrativo (Pena 1984, 77).

Con los datos de la arqueología, Tarraco se había considerado fundación romana ante la falta de indicios arqueológicos anteriores a época republicana en su solar, pero el registro, ya hace años de restos 
ibéricos desde el s. v en el mismo, delatando un importante poblado (Adserías et al. 1993), invalidaron esa creencia. Posteriormente, los datos sobre el mismo han aumentado. Recientemente se ha propuesto la posibilidad de la previa convivencia de la población ibérica con la fortificación romana de los Escipiones y una posterior posible fundación romana de la segunda mitad del s. II por parte de Escipión Emiliano - con ello sería cierto lo de Scipionum opus - siendo, como antes se indicaba, una dipolis hasta época cesariana (Járrega 2004).

El que a partir del s. II no se acuñe más con el nombre de taŕakon, convirtiéndose kese en la más importante ceca del nordeste, redunda en que debía tratarse de la posterior capital provincial. Los cesetanos o cosetanos nos aparecen ubicados en el campo de Tarragona, teniendo como vecinos a los ilercaones o ilercavones al sur, los layetanos al norte y los ilergetes - y quizás los lacetanos si se puede hablar de este pueblo- al oeste, y no contó, ni en el s. II ni en el siguiente con ninguna otra ceca conocida. Kese hace referencia evidentemente a este pueblo y presumiblemente debe tratarse de su ciudadcabecera o, si queremos, su capital y esta no podía ser sino Tarraco en los momentos que tratamos.

En su momento sostuve que las más antiguas monedas tarraconenses eran las dracmas con leyenda taŕakon, aunque se expresaran dudas sobre su atribución (Campo 1997, 43) hoy no aceptadas tras la aparición de nuevos ejemplares (Villaronga 1998, 150), a las que siguieron las de kese. Consideré la posibilidad de que no hubiera dracmas con este último nombre, en razón de que los pocos ejemplares atribuidos presentaban cierta dificultad en su lectura (Villaronga 1983, 43; Id. 1994a, 52 núm. 103; Id. $1998,156)$ hasta el punto de que se había propuesto situarla entre las cecas dudosas, pudiendo tratarse incluso de una leyenda no auténtica o una imitación sin sentido (De Hoz 1995, 319). Por ello parecía prudente no pronunciarse tajantemente hasta que nuevos ejemplares con lectura más segura aclararan el problema. A pesar de ello se dio posteriormente por cierta su lectura (García-Bellido \& Blázquez $2001,32,240)$. Otro problema es que a los primeros bronces de kese se les suponía anteriores a 220 a.C., pues el metal y la metrología los relacionan más con el mundo hispano-cartaginés que con el emporitano-ibérico, y según L. Villaronga, con la metrología propia del sur de Italia y Sicilia. Incluso la tercera de sus emisiones presenta los mismos cambios metrológicos de esos lugares (Villaronga 1983, 101$102,118)$. No soy quien para contradecir a los especialistas en numismática, pero quisiera recordar una vez más que desgraciadamente no hay confirmación arqueológica de ello y que en principio parecería más plausible suponerlas de los primeros tiempos de presencia romana y llevar los primeros bronces al s. II, o como mucho muy a fines del anterior. No obstante, si ello fuera cierto, taŕakon y kese pudieron acuñar al unísono. La explicación de que la primera leyenda alude a la ciudad y la segunda a los habitantes de la misma y sus alrededores (Villaronga 1998, 156), no parecía convincente, pero de alguna manera venía a sugerir que se trataba de la misma localidad.

El problema volvió a adquirir primacía con la publicación de unos singulares divisores de dracma, concretamente una hemidracma y dos óbolos con leyenda clara, uno de ellos keseśalir y los otros kese$k u$, a los que no se ha tenido en cuenta en trabajos recientes que trataban de la cuestión, lo que extraña siquiera sea por la importancia que tiene el que por primera vez se documenten divisores de esta ceca. Es cierto que el primer divisor conocido, horadado en la parte de la leyenda (García Garrido-Montañés 1989,48 ) planteaba algunas dudas y fue incluido por L. Villaronga entre los divisores inciertos de finales del s. III (Villaronga 1994a, 78 con leyenda kes?ku), pero no en su posterior estudio sobre las dracmas. Las dudas se despejaron con la publicación de las otras dos piezas en que la lectura no ofrecía problema alguno (España 2000; Benages 2001, 18, 22-24), siendo recogidas como una «serie rara» en la reedición, puesta al día, de la veterana obra sobre la numismática antigua de Hispania de L. Villaronga, aceptando su autenticidad (2004, 110-111).

Se trata de unas piezas originales por varios motivos. En primer lugar el sufijo -śalir, interpretado de antiguo como «plata», era hasta ahora exclusivo de las dracmas, sobre todo de las de iltiŕta, pero también de las de taŕakon, iltiŕke, belse, eru y olośrnŕ.betase (Villaronga 1998, 158), y en ningún caso aparecía en los pocos divisores conocidos. En lo que respecta a $-k u$, ya hemos visto que aparecía también en dracmas. En segundo lugar, singular es asimismo la iconografía de estas piezas: cabeza de medusa de frente en el anverso y lobo en el reverso. La medusa, con pelo ensortijado, no se representa con la lengua fuera, como es corriente en los modelos en que sin duda se inspira, pero con todo nos remite a Sicilia, e incluso Etruria o Tracia, aunque no sea de forma mimética. En todo caso no hay paralelos en dracmas y divisores ibéricos. En cuanto al lobo, es bien conocido como motivo característico de iltiŕta, tanto aislado como bajo Pegaso en dracmas y junto a ruedas en divisores como después lo seguirá siendo en sus monedas de los s. II y I (Pérez-Soler 1993), pero también bajo Pegaso 
aparece en las menos prolíficas cecas de oŕose y belsekuai —en esta, en una dracma, jabalí en vez de lobo- (Villaronga 1994a, 41 ss.), pero en ningún caso en monedas de kese, en cuyas dracmas aparece un delfín bajo Pegaso, que se representa también en monedas posteriores, salvo que el interpretado como perro con las costillas marcadas fuera en realidad un lobo como en las monedas de iltiŕta. No obstante aparece en escaso número, al igual que el caballo, también en ocasiones representado.

La cronología plantea dudas, como por lo demás también para el resto de dracmas y divisores —el que la $k$ en creciente sea antigua no nos sirve para el caso-, con lo que se nos vuelve a plantear si kese y taŕakon correspondían a dos ciudades diferentes, aunque próximas, o se trataba de la misma. Le evolución posterior de las cecas, hemos visto, nos inclina a pensar que se trata de la misma, pero no podemos aseverar si una leyenda precedió a la otra visto el breve segmento cronológico que se atribuye a estas primeras monedas ibéricas del s. III aunque, por otro lado, su circulación se prolongara hasta aproximadamente el año 180 (Campo 1990, 40). Tarraco no vuelve a aparecer en la numismática hasta poco antes del cambio de era, ya con caracteres latinos, cuando era colonia - desde época de César, unas décadas antes de la emisión de estas monedas- y capital provincial. Dejará de hacerlo tras Tiberio, aunque excepcionalmente acuñara en tiempos de Galba durante la crisis del 69. El por qué este nombre desaparece durante toda esta etapa no está claro, sobre todo si se repara en que la ciudad es durante mucho tiempo el único centro romano del nordeste peninsular mencionado con este nombre por las fuentes. Podemos admitir que en ella, junto al aparato romano, las elites indígenas componían un ente político (¿el cesetano?) que sí emite. Teniendo en cuenta que durante mucho tiempo la moneda no fue acuñada para usos comerciales, sino para el pago de unos servicios necesarios a la administración (García-Bellido 1993b, 99), pagos que harían las ciudades indígenas, no las romanas o latinas, Roma optaría por el nombre del pueblo indígena de la zona - o uno de los dos nombres de la ciudad - quizás como cabecera de una circunscripción, lo que haría después con los otros principales pueblos con las monedas en -sken del s. II.

\section{ILTIŔKE-ILTIŔKESKEN, CASO POLÉMICO}

Tan longeva como kese, aunque no tan prolífica, es la ceca de iltiŕke-iltiŕkesken que emite desde el s. III hasta un momento indeterminado del I. M. Cam- po $(2005,78)$, que la considera lacetana, cree a través del conjunto termal de Can Mateu, que h. 90 la ceca ya había emitido la mayor parte de su producción, pero pienso que es posible que ya entonces hubiera dejado de emitir definitivamente, si bien en fecha reciente. Es por lo demás, también junto con kese la única cuyo nombre nos pone en contacto con un étnico - en realidad con dos como veremos-en dracmas y divisores. En el s. II e inicios del i sólo acuñó bronces, aunque se le haya atribuido un denario de la Biblioteca Nacional de París (Collantes 1997, 248). ¿Es posible que la localidad emisora tuviera otro nombre como en el caso anterior? Desde el s. II aparece en genitivo -iltiŕkesken-, pero también con la forma iltiŕkes - ¿abreviación del genitivo?, nos hemos referido a ello- - y, antes en dracmas iltiŕkeśalir, con lo que evidentemente se está refiriendo a una localidad en nominativo. Siguiendo el proceso conocido del paso del ibero al latín, en que la $t$ tras la $l$ es muda, la segunda $i$ se transmuta en $e$, y la $k$ equivale a $c$ o $g$, nos daría una lectura latina para la ciudad de Ilerca o Ilerga (De Hoz 1995, 320), nunca mencionada ni por las fuentes ni por la epigrafía, pero que nos sugiere dos de los más significados étnicos conocidos y que a su vez designan a dos regiones de Plinio, los ilergetes y los ilercaones o ilercavones, el primero el más importante sin duda en cuanto a extensión territorial de la actual Cataluña, con centro en torno al Segre y extensión hasta la zona de Huesca incluyendo esta ciudad, el segundo ubicado en el Bajo Ebro.

Si se tratara de los ilergetes y teniendo en cuenta que ostentando el nombre del étnico sería, o habría sido, su ciudad más importante, el problema es que no sólo no nos consta ninguna con ese nombre y una ceca, iltiŕta, la posterior Ilerda, ejerce con sus abundantes emisiones una capitalidad monetaria indiscutible. El nombre de la última está aparentemente relacionado con el étnico, pero no es cierto: si así fuera habría que pensar en unos hipotéticos ilerdetes o ilertetes. Emite desde el s. III y continúa en los dos siglos siguientes (Pérez Almoguera 1996, 42), constituyendo la ceca más importante del interior. Incluso en el s. II acuña plata en un número superior a kese (Campo 2002, 84) y junto a esta y a untikesken, es la que tiene más continuidad (Villaronga 1994b, 28). Coincide la cronología de sus emisiones con las de iltiŕke, por lo que en principio habría de tratarse de dos cecas diferentes, salvo que se pensara que se produjo un caso similar a kese-taŕakon que pudieron emitir al unísono tratándose de la misma localidad, pero, como hemos visto, ello ocurrió en un breve periodo de tiempo y no es el caso que nos 
ocupa. Otra cuestión relacionada con el doble nombre, es la identificación o no de iltiŕta con Atanagrum, mencionada en una sola ocasión por Livio (31, 61, 6-7) como cabecera de los ilergetes en acontecimientos del año 218, con lo que pudiéramos encontrarnos con un doble nombre que desde luego no se correspondería en los dos casos con el étnico. Por los mismos motivos Atanagrum podría ser iltiŕke si esta era ilergete, aunque ello no pase de ser una especulación, pues la realidad es que ninguna otra fuente se refiere ni a una ni a otra. La anomalía que representa la mención de Livio se ha tratado de explicar, sin éxito, en diversas ocasiones (Pérez Almoguera 1999). En cualquier caso, al no afectar a la numismática es un problema en el que no incidiremos más.

La mayoría de especialistas en numismática han supuesto a iltiŕke ceca ilergete y se han buscado diversas explicaciones para separarla de iltiŕta. Ya en 1931 J. Hill creyó que la últimas era para uso interno representando a la ciudad, mientras las de iltiŕke representarían al pueblo ilergete (Garcés 2002, 188), con lo que podría tratarse de la misma ceca. En contra podría argüirse la abundancia de iltiŕta sobre la otra y la citada duración de ambas, aunque es cierto que en el s. II iltiŕke sólo acuñó bronces.

L. Villaronga (1961), tras el estudio del tesoro de Balsareny, propuso dos cecas distintas dentro del territorio ilergete, iltiŕke correspondería a los ilergetes orientales - comarcas de la Segarra o el Solsonés-, el iltiŕta a los occidentales, opinión sostenida también por J. Untermann (1975, A-19, 206; TIR $\mathrm{K} / \mathrm{J} 31,91)$, en atención a los hallazgos, abundantes en el territorio comprendido entre Solsona, el Cardener, la Segarra y el Plà de Bages. La opinión de que iltiŕke sería la principal ciudad ilergete a fines del s. III, quizás oriental, y la posterior iltiŕta se situaría en territorios más al este conquistados posteriormente en un momento impreciso (De Hoz 1995, 320-321), parece contradecirse por el hecho de emisión de dracmas al unísono y por el hecho de que la arqueología muestre una temprana iberización en la zona ilerdense. Aún más recientemente se ha propuesto identificarla con el antecedente del municipium altoimperial de Sigarra que conocemos por la epigrafía, indicando su notable presencia en Iesso (Guissona) y sobre todo en Els Prats del Rei donde su ubica el municipio Sigarrense (Guitart-Pera 2004, 194). Allí, en sondeos realizados hace unas décadas, de 20 monedas recuperadas 19 correspondían a iltiŕkesken. Incluso recientemente se ha llegado a proponer de forma forzada para encajar con las fechas que parecen desprenderse por la arqueología de la fundación de Sigarra, que sus primeras emisiones habría que llevarlas, en contra de lo sostenido, a una fecha tardía, fines del s. II o inicios del I — ijustamente en el momento que se considera que han desaparecido o desaparecen las que presentan el genitivo -sken de los etnónimos y la arqueología muestra nuevas fundaciones que parecen indicar una nueva organización territorial!- , haciéndolas contemporáneas de la nueva fundación, o refundación, romana de Sigarra (Padrós 2005, 527) sin tener presente la brevedad del lapso de tiempo que habría entonces que suponer para el amplio número de sus emisiones, e ignorando, y ello es más importante, que iltiŕke ya emitió dracmas, como hemos visto a fines del s. III o inicios del II. Además, la aparición de un tritetartemorion de una desconocida ceca de sikarbi o sikara (Villaronga 1994a, 513, núm. 31; Marqués de Faria 2000, 64 propone leer sigara) hace que se suponga que su nombre era ya a fines del s. III el que tendría después el futuro municipio. Sin embargo, a pesar de ser conocida por este única moneda, es interesante reseñar que en las que aparece la leyenda iltiŕkeśalir se representa en su reverso un jinete con pilum y escudo redondo a la espalda, como en sikara, y que Ptolomeo en el s. II d.C. sitúa, y ello lo creemos de sumo interés, a Sigarra como localidad ilercavona (II, 6, 66). Si a los ilercavones se les sitúa en el Bajo Ebro, por la situación geográfica de Els Prats de Rei, es difícil admitir su adscripción a esta etnia, por lo que suele considerarse un error del alejandrino (Pera 1994), y más concretamente «una disposición aberrante que se desencuadra del étnico en que se incluye» (Gómez Fraile 1997, 200). ¿A que podría deberse esta adscripción? No sería el único caso en que se ha supuesto un error: similar es el caso de la adscripción de Gerunda a los ausetanos, Iacca a los vascones, o Celsa a los ilergetes.

En principio podemos pensar que si Els Prats de Rei era sikara no podía ser iltiŕke (Pérez Almoguera 2001-2002), salvo que supusiéramos un caso paralelizable a kese-taŕakon, lo que parece poco probable al ser este último un caso singular como hemos visto y significaría identificar sikara con la cabecera de los ilergetes o de los ilercaones y nada hace pensar en ello.

Otras propuestas de ubicación, como el yacimiento de cierta entidad de Monteró, junto a Camarasa donde predominan entre las de bronce (Crusafont 1989), carecen de argumentación fundamentada.

La dispersión de las monedas de iltiŕke es amplia, pero son sobre todo abundantes en el occidente barcelonés y el oriente leridano como hemos visto. Sólo este motivo explica que recientemente se haya considerado, a nuestro entender de manera equivocada, 
ceca lacetana (Campo 2005, 78) e incluso layetana (Villaronga 1994a, 200). Si así fuera, en ambos casos no se trataría de un etnónimo y, en Cataluña, todos los genitivos -sken corresponden a alguno. Pero también es frecuente en las zonas ribereñas del Ebro, a través de cuyo afluente principal, el Segre, llegan al mediodía galo donde fueron imitadas. También se ha propuesto que estas imitaciones se explicarían mejor si se tratara de una ciudad marítima (GarcíaBellido \& Blázquez 2001, 187), y aquí entra la posibilidad de relacionarla con los ilercavones.

Es en efecto discutida su relación con este último pueblo, centrado en el Bajo Ebro, y aún más considerarla la antecesora de Dertosa, su principal localidad altoimperial, la actual Tortosa (Pérez Almoguera 1995, 311-325; Id., 1996, 41), que emite en tiempos de Augusto y Tiberio con la lectura MVN. IBERA IVLIA y en el reverso ILERCAVONIA (Villaronga 1994a, 172, núms. 1-4). ¿Por qué se indica en ellas la referencia al étnico o a la región de los ilercavones cuando no se hace en la titulatura de cualquier otro municipio? Parece un recuerdo de iltiŕke pasado al latín (=Ilerca), es decir, en su nomenclatura municipal seguiría apareciendo el nombre de la ciudad anterior. Un dato a remarcar es, en cualquier caso, que la monedas de Dertosa de época de Tiberio presentan en el anverso la contramarca de palma, lo que ocurre también con las de iltiŕke de lo que ya había llamado la atención Villaronga (Diloli-Corominas-Arola 2001, 546). Los divisores de bronce del s. II representan en el anverso un protomo de caballo o medio Pegaso. Lo cierto es que de no ser una ceca ilercavona, se trataría junto con el posible de los ilergetes que hemos visto, de la única de las regiones que cita Plinio en el nordeste que no contaría con ceca homónima durante el s. II. ¿Significaría ello que, ocupando los ilercavones el Bajo Ebro y parte de la provincia de Castellón, el río $\mathrm{Hi}$ berus vendría a marcar lo que podríamos denominar una frontera monetaria y se vio excluida de esta organización nororiental?

La atribución a los ilercavones no es nueva. Ya en el s. XIX J. Zobel propuso la posibilidad de que se tratara de una ceca tarraconense y Botet i Sisó se aventuró a apuntar a este pueblo (Garcés 2002, 188), lo que volvió a proponerse en la década de los sesenta y en las siguientes del pasado siglo (Martín Valls 1967, 49, 108; Fatás 1993a, 226). Sería además la Hibera de la Segunda Guerra Púnica (Liv. XXIII, 26-28), nombre que también conservará Dertosa en su titulatura municipal como muestran las citadas monedas. Es cierto que las fuentes escritas no mencionan a ambas conjuntamente, lo que no obsta para considerarla la misma. En resumen según esta postura, iltirke sería la misma localidad que Hibera y Dertosa (Pérez Vilatela 1991, 219; Diloli 1996, 44). Una explicación de ello podría concretarse en que Dertosa fuera el nombre de la localidad, Ilerca el de la civitas que vertebró el territorio, e Hibera haría alusión a su ubicación a orillas del Ebro controlando su desembocadura. Si Hibera era uno de los nombres de iltiŕke, extraña que Livio no se refiera a ella con este nombre (Llorens-Aquilué 2001, 15), pues Hibera se menciona en la Segunda guerra púnica y dada la antigüedad de las monedas de iltiŕke podían ser contemporáneas. Con todo, no parece que sea un argumento contundente: las fuentes tampoco mencionan a laie, auso o untika y en el s. II emiten con estos nombres.

Parecía apuntar en la dirección de que se tratara de una localidad marítima el que se hubiera propuesto para iltiŕke un inicio de sus acuñaciones a mediados del s. III, fecha muy temprana, anterior a las otras cecas catalanas que acuñaron dracmas (García-Bellido \& Blázquez 2001, 187), en virtud de su iconografía - cabeza varonil- que parecían imitar estáteras de Tarento (Villaronga 1994a, 36, núms... 46-47, 50-53; 514, núm. 50B). La documentación de la misma cabeza en ejemplares de iltiŕta (Villaronga 1998, 70, 112) hizo rectificar esta apreciación y se convino que no podía ser anterior a 218 .

Más dificultad hay en identificarla con la Tyriche que menciona Avieno en la desembocadura del Ebro (o.m. 496-503) como ciudad rica y antigua, pero señalemos — quizás no pase de ser una casualidadla similitud del nombre con iltiŕke $e^{2}$. Lo que no parece posible, como bien estudió M.J. Pena (1989), es que haya que pensarse en un origen tirio para la misma.

Si se trata de la antecesora de Dertosa, no hay desde luego que suponer forzosamente que su núcleo urbano se ubicara en el mismo lugar que el del $m u$ nicipium, pues aunque, hasta hoy, la arqueología muestra que los restos en Tortosa apenas alcanzan los últimos decenios previos al cambio de era (Genera 1993), se supone fundada o reubicada, como tantas otras, a fines del s. II o inicios del I (Diloli 1996, 44).

Expuesto los argumentos de las posibles adscripciones - a ilergetes o a ilercavones-, el problema vemos que dista de estar resuelto, pero tengamos presente que los ilergetes contaron con una auténtica capital monetaria, la prolífica iltiŕta que en el aspecto monetario jugará en el interior el mismo papel que

${ }^{2} \mathrm{Si}$ el nombre de esta localidad lo precedemos del sufijo $-i l$, tan frecuente en tantos topónimos y antropónimos ibéricos, nos daría Iltirica. 
kese en la costa, lo que hacía que los ilergetes se identificaran con ella. Esta singular riqueza monetaria esta en relación directa con la de este pueblo y el papel que jugó en la Segunda Guerra Púnica. Si se considera que los pueblos ibéricos del nordeste contaban con un $50 \%$ dedicado a cereal, en la zona ilergete llegaba al $75 \%$ (Alonso 2000). Otro hecho a tener en cuenta es que, en casi todos los casos, no sabemos si las etnias ibéricas estaban fragmentadas en diversas entidades políticas o bien constituían una sola, pero para los ilergetes durante la Segunda Guerra Púnica parece que etnia y territorio político se identifican (Sanmartí-Santacana 2005, 31) pero en contra juega que las etnias no constituían estados centralizados, pero si fuera cierto dada esta identificación de todo el territorio con iltiŕta no era necesario establecer entre ellos por parte romana una ceca con el nombre del populus. Ello redundaría en una probable pertenencia de iltiŕke a los ilercavones, pero no podemos sostener una u otra adscripción basándonos en argumentos aparentemente lógicos, pero sin comprobación. El problema, como expresé en otra ocasión, sigue igual de abierto como cuando hace una década A. Domínguez $(1997,128)$ se refería a que la dispersión conduce a situarla en torno a Solsona «aunque también se ha propuesto Dertosa (Tortosa)».

\section{LAS OTRAS CECAS DEL ÁREA «IBÉRICA» CON NOMBRE ÉTNICO}

Las que evidentemente ostentan un nombre relacionado con étnico en el s. II las relacionaremos por orden alfabético. El mayor o menor espacio que se les dedica es consecuencia del mayor o menor problema que plantean y en modo alguno reflejan otro tipo de graduación.

auśesken.-Es la única ceca que en el s. II emite plata junto a kese e iltiŕta, aunque en menor cantidad que estas (Villaronga 1994a, 185), pero en cualquier caso ello indica capitalidad regional. No consta que hubiera dracmas con este nombre y no hay indicios de que pudiéramos suponerla sucesora de otra con nombre distinto. Su lectura nos remite sin duda a los $a u$ setani, mencionados sobre todo por Livio en sucesos de la Segunda guerra púnica $(21,23,2 ; 21,61,8 ; 29$, $2,5 ; 29,3,3 ; 34,20,1 ; 39,56,1)$ donde aparece como uno de los populi más importantes, unido a veces en alianza con los ilergetes, pero también con anterioridad si se suponen los sucesores de los ausoceretes de Avieno (ora 550). No es la única ceca ausetana, pues también se considera tales a ore y a euśti-euśtibaikula que tampoco emitieron dracmas.

Todos los indicios redundan en considerarla la ciudad principal ausetana (Untermann 1992, 25) que habría dado nombre al pueblo (Pérez Almoguera 1993-1994) y no a la inversa como se ha defendido (Mangas 1996, 44). Citada como ciuitas por César (b.g. 1, 60; Keay 1996, 164), será el posterior municipio altoimperial de Auso o Ausa, la actual Vic, citada por Plinio $(3,22)$ y posteriormente por Ptolomeo (II, 6, 66). Que la arqueología parezca indicar un reducido núcleo urbano no es motivo para no suponer su primacía, dado que ello parece ser una característica de los municipios imperiales del interior catalán. El nombre ha perdurado en la actual comarca de Osona (de Ausona) si bien según Ptolomeo el territorio de los ausetanos sería más amplio, abarcando la cuenca del Ter incluyendo la ciudad de Gerunda, lo que no suele aceptarse por motivos geográficos (Burch-Nolla 1995).

Una cuestión que no podemos dejar al margen es la posible existencia de un pueblo homónimo situado en el Bajo Aragón. Frente a la opinión generalizada, ello ha sido aceptado, sobre todo por investigadores aragoneses, sosteniendo que los ausetanos de Cataluña no constituían el pueblo que tuvo tan importante papel en los acontecimientos de 218 (Jacob 1987-88; Burillo 1998, 134; Id. 2001-2002), sino que se trataría de otro situado al sur del Ebro, con el que incluso se han querido relacionar las estelas funerarias prelatinas bajoaragonesas. Para ello se sigue la aparente lógica de las campañas que refleja el texto de Livio que los ubica no lejos del gran río $(21,61)$. Con respecto a ello ya se había insinuado que tal ubicación era un error de Livio (Beltrán 1984, 169), cosa no extraña, pues cuando el autor relata sucesos que no tienen lugar en la costa estricta las descripciones son poco precisas (Richardson 1986, 35 ss.), además de escuetas y breves. Sin entrar en la polémica, lo seguro es que las monedas se refieren a la ciudad cabecera de los ausetanos de Cataluña, al igual que las fuentes escritas imperiales.

laieśken.-Las monedas exclusivamente de bronce del s. II con esta leyenda se relacionan sin problemas con los laietani que habitaban las comarcas barcelonesas del Barcelonés, el Vallés y el Maresme. Este pueblo es citado en diversas ocasiones por las fuentes escritas, también como laeetani, y a veces confundido por su homofonía con los lacetani, cuestión sobre la que volveremos más adelante. Estas fuentes en ninguna ocasión se refieren a una localidad de nombre Laie, que sería la emisora. Ha privado sin 
embargo la creencia que la moneda se refiere a un étnico y no a una localidad (Villalonga 1994a, 191), en cuyo territorio había otras cecas que acuñaron con nombres de ciudades. Tales son baitolo, euśtibaikula - no es seguro si fue layetana o ausetana- o ilturo y quizás la no ubicadas de abariltur, lauro y ośkumken, que lo hicieron, también en bronce, a la vez que laieśken en buena parte; sólo baitolo es con seguridad posterior. Sin embargo nuestra opinión varias veces expresada es que corresponde a una ciudad que a su vez había dado origen al nombre del populus. Como en otros casos, cabe la posibilidad de que la localidad emisora tuviera más de un nombre.

No hay dracmas con este nombre, pero si que las hay con el de una única ceca layetana, baŕkeno de la que se conocen cuatro ejemplares con leyenda nítida (Untermann 1975, 180; Villaronga 1979, 113; Id. 1994a, 49; Id. 1998, 154) a las que hay que añadir otras con leyenda bakerno y otra con leyenda invertida de derecha a izquierda (Collantes 1995, 329-330), nombre que evidentemente nos remite a Barcino, Barcelona, colonia desde época augustea -Fauentia Paterna Barcino - que recupera, tras dos siglos de silencio en la numismática y las fuentes escritas, el nombre que tenía a la llegada de los romanos, prueba de que este no se había perdido aunque no aparezca en ningún tipo de documento durante dos siglos. Aunque no acuñará con posterioridad, es suficientemente mencionada por las fuentes escritas y la epigrafía. Sin embargo no han dejado de ponerse objeciones y se ha supuesto que estas dracmas no corresponden a la antecesora de Barcino (Campo 1997, 43), sino a una ceca ubicada en el área dominada por los cartagineses en la Segunda Guerra Púnica, opinión que no es generalmente compartida.

Aceptada la identificación, no creemos arriesgado suponer que a fines del s. III baŕkeno era la principal localidad layetana. Las monedas de laieśken siguen cronológicamente a las anteriores, ¿pudiera tratarse de la misma localidad? Lo creemos posible, con lo que nos encontraríamos ante otro caso de doble nombre como kese-taŕakon. Las principales objeciones en contra no parecen de peso: al que los hallazgos de monedas de laieśken se encuentren principalmente en el interior, que han propiciado que se ubique en una lugar desconocido del Llobregat medio (Villaronga 1982, 169), se puede oponer el que, por el mismo motivo, iltiŕta - por hablar de la ceca más conocida, sin que sea un caso único- habría que situarla en la costa. En cuanto a que no parece creíble que estuviera tan cercana a otra ceca como fue baitolo, el posterior municipio de Baetulo (Badalona), se puede argüir el que la última no emite hasta ini- cios del s. I, o como muy pronto en el tránsito del II al I, momento de su fundación y cuando laieśken ha dejado ya de hacerlo (García-Bellido \& Blázquez 2001, 52-53), con lo que no son por tanto contemporáneas. También se ha hecho notar que, hoy por hoy, el principal poblado layetano en cuanto a extensión a inicios del s. II era el de Burriac, en Cabrera de Mar, identificado con la ceca de ilturo, que fue destruido por Catón y reocupado unos cuantos decenios después (Sanmartí-Santacana 2005, 186), pero no creemos posible que correspondiera a la ceca de laieśken, no tanto por su empequeñecimiento tras las campañas de 195, sino porque emite con el citado nombre de ilturo durante todo el s. II (García-Bellido \& Blázquez 2001, 196-198) cuando también lo hace la ceca con el nombre del étnico.

La colonia augustea se fundó ex novo en el llano de Barcelona, lo que presupone que su predecesora indígena y republicana no se encontraría muy alejada. Los datos con que contamos nos mueven a situar el principal núcleo prerromano en la montaña de Montjuic, orientado hacia la desembocadura del Llobregat, donde podría situarse el puerto. Tal poblado ha desaparecido por los diversos trabajos de envergadura efectuados en la montaña y sus inmediaciones, pero se ha llamado la atención de que podía tener una extensión similar al de Burriac, aunque no se puede asegurar por lo poco que de este sabemos. Por otro lado, la investigación de unos silos de gran tamaño indican allí un importante centro comercial desde el s. IV cuando menos (Padró-Sanmartí 1992, 191; Blanch et al. 1994; Barberà-Dupré 1984, 67), lo que abunda en su posible papel de cabecera del populus. No es pues del todo cierto que no se acepte que pueda ser Barcelona por falta de pruebas arqueológicas o documentales (Domínguez 1997, 127).

sedeisken.--Es un genitivo que se relaciona con los sedetani, el pueblo ibérico más oriental ubicado en el valle medio del Ebro, al oeste de los ilergetes, claramente diferenciado de los edetani, a pesar de la confusión que había generado un pasaje de Ptolomeo que hacía edetanas a ciudades sedetanas (Fatás 1973; Untermann 1992, 24), por lo que carece de sentido suponer la emisión de las monedas de sedeisken en Edeta (propuesto por Tovar 1989, C-549, T9) o en otro lugar levantino. Tales monedas se fechan en la primera mitad del s. II, constituyendo la más antigua ceca de este pueblo (Beltrán 1993, 248; Burillo 1995, 168), al que se atribuye un amplio territorio y que cuenta además con más cecas sobre todo desde la mitad avanzada del s. II: kelse, alaun, lakine, iltukoite, otobesken, saltuie y usekerte — si bien las dos prime- 
ras no es seguro que fueran sedetanas-, en general poco prolíficas (Domínguez 1997, 146). La cuestión es que si el nombre de un étnico corresponde al de una localidad que, al menos en un tiempo, fue la más importante del mismo y dio nombre a un populus, no aparece ninguna con este nombre ni en las fuentes escritas ni en ningún otro tipo de documento, pero si en las propias monedas que también en el s. II emiten en nominativo con leyenda seteis - no creemos que se trate de una abreviatura del genitivo-, pero por lo expresado del silencio de cualquier otro documento nos preguntamos si pudo tener otro nombre. La realidad es que no hay ninguna conocida que pueda suponérselo. Aunque se siga sosteniendo que son propias de un étnico y no de una ciudad (Villaronga 1994a, 219), G. Fatás indicó, a mi entender acertadamente, que sedeis fue un lugar que debió de representar entre los sedetanos el mismo papel que Edeta entre los edetanos o kese entre los cesetanos (Fatás 1989, 402; Beltrán 1996, 31) y que se trató de una ciudad importante se desprende de su buena representación en el tesoro de Azaila, aunque no deja de llamar la atención el que no acuñara plata (García-Bellido \& Blázquez 2001, 350). Su ubicación, desconocida, se supone en el Ebro, quizás cerca de donde desemboca su afluente Aguas Vivas (Burillo 2001, 193). Tradicionalmente se ha venido suponiéndola en Sástago sin argumentos sólidos (Domínguez 1979, 41; Burillo 1996, 104; Beltrán 1996, 90). El área de dispersión de sus monedas no ayuda tampoco a su ubicación (Beltrán 1995, 104) y se ha apuntado que pudiera tratarse de una de las ciudades que en el valle medio del Ebro desaparece en beneficio de otras que luego encontramos con importancia política y que acabarán tornándose en romanas (Martín Bueno 1993, 110).

Desde inicios del s. I la ciudad que destaca entre los sedetanos en saltuie, la antecesora de la colonia Caesaraugusta, que contará con una sola emisión, también en bronce, en el tránsito del s. II al I, en un momento en que seteisken ya no lo hace. Su importancia vendrá acrecentada por el hecho cercano cronológicamente de ser elegida por la administración romana como centro de reclutamiento según el conocido Bronce de Ascoli o Turma Salluitana, en un lugar fronterizo entre iberos, celtíberos y vascones.

¿Es posible que esta condición fronteriza sea causa del traslado del centro principal del populus a esta en detrimento de sedeis? En este sentido podría considerarse a saltuie como sucesora de la anterior, pero no en cuanto a ubicación, pues no hay el menor indicio que nos haga suponer que era la misma localidad con doble nombre como en otros ejemplos que hemos visto.
saltuie.-Según la arqueología, es una más de las nuevas fundaciones «a la romana» del nordeste de fines del s. II y, sobre todo, inicios del I, pero con habitantes y rectores indígenas. La fecha es cercana al citado Bronce de Ascoli y también a la tabula aenea Contrebiensis donde también aparece mencionada. En el s. I emite también kelse, futura colonia Celsa al este, pero por su situación se ha dudado que fuera sedetana - Ptolomeo la considera ilergete- o en cualquier caso ciudad fronteriza (Beltrán 1996, 49), aunque en la segunda mitad del s. II parecía destinada a ocupar en una amplia región el papel que tendría después Caesaraugusta, la sucesora de saltuie.

untikesken.-Esta ceca, sin discusiones atribuida a los indiketes, ubicados en 1'Empordà, emite, como ceca única de este pueblo, desde inicios del s. II exclusivamente en bronce - ases, semis, cuadrantes y sextantes - hasta un momento impreciso de la primera mitad del I, siendo además una de las pocas en que aparecen nombres de magistrados indígenas —algunas veces nombres latinos iberizados - y marcas de valor (García-Bellido-Blázquez 2001, 387). Una única fuente, tardía, menciona una localidad de nombre Indica (Steph. Byz. 146), que no sería sino el nombre de la ciudad indígena que con la griega Emporion constituía una dipolis (Untermann 1975, A-6, 165-172). Si así fuera, se explicaría que no acuñara plata; ya lo hacía la ciudad focense que emitía dracmas y divisores desde el s. v, aunque no hay unanimidad en cuanto al momento en que dejó de hacerlo, pues si se ha propuesto que ello ocurrió en la primera parte del s. I, otras veces se ha hecho en el meridiano del s. II (Campo 1997, 47) siendo de bajo peso sus últimas dracmas tras acuñar gran cantidad durante la Segunda Guerra Púnica. En cualquier caso sabemos, por los tesoros, que continúan circulando hasta las primeras décadas del I. También se ha propuesto que la no acuñación de plata de $u n$ tikesken pudiera deberse a que, al ser aliada de Roma, pudo verse libre de los pagos que debían de satisfacer otros pueblos (García-Bellido 1993 b, 113).

No es sin embargo unánime la opinión de ubicar Indica en Emporion, e incluso tampoco que existiera una localidad con este nombre. Admitiendo que su existencia fuera real, se ha llamado la atención de que pudiera tratarse de Ullastret (Sanmarti-Santacana 2005, 35), el poblado ibérico más extenso de los conocidos indigetes que llegó a ocupar 17 ha en el ibérico pleno, es decir entre 400-200. Sin embargo la destrucción del mismo en las campañas de Catón representó prácticamente su desaparición, restando sólo una población residual (Martín 1997, 15), por lo que parece más plausible situar la ceca en Emporion. 


\section{LAS CECAS OCCIDENTALES DE SESARS Y BAŚKUNES-BAŔŚKUNES}

Nos hallamos ante dos cecas al occidente de las anteriores, evidentemente no ibéricas como éstas, una quizás vascona y la otra celta que además no está claro, como veremos, que sus nombres aludan a étnicos aunque en muchas ocasiones ello se ha sostenido.

sesars.-Se ha querido ver su relación con los suessetani, pueblo que suele situarse en el norte aragonés, junto a los sedetani, con centro en las Cinco Villas aunque también se ha propuesto hacerlo más al oeste (Fatás 1993a), incluso en tierras vasconas. Posiblemente contaban con un sustrato vascón con influencias ibéricas claras (Beltrán 2006, 225). Tal pueblo es mencionado exclusivamente en sucesos situados entre 211 y 184 a.C. por las fuentes, por lo que se ha supuesto que pudo ser absorbido posteriormente por otros (Plácido 1997, 56), aunque en contra estaría la posible mención de Plinio como una de las regiones a la que pertenece Osca-Suessetania, mejor que Uessetania, nombre desconocido por otras fuentes escritas o numismáticas- $-(n . h .3,24)$ y el que si sesars se refiere a ellos era importante en torno a mediados del s. II, pues, aunque en una producción limitada, emitió plata. En los primeros decenios de este último siglo se cita su capitalidad en Corbionem, localidad de ubicación desconocida destruida en 184 .

sesars emitió también bronces (García-Bellido \& Blázquez 2001, 349), pero tanto en plata como en bronce en el s. II, con una cronología ante quem de 133, constituyendo, significativamente las primeras emisiones monetarias de Aragón (Villaronga 1994a, 209) al menos en lo que a plata se refiere. Deja de emitir en la segunda mitad de siglo sin que, como hemos visto, podamos precisar la fecha, pero no deja de ser llamativo que Osca, ubicada según Plinio en la región suesetana, también emitiera plata y bronces con la leyenda bolśkan en la segunda mitad del s. II, en un momento incierto, llegando hasta inicios del siglo siguiente. Aunque se ha propuesto la leyenda bolśken (Rodríguez Ramos 2001-2002, 432-433), con la que nos encontraríamos ante otro genitivo en -sken, la versión latina del nombre, Osca, parece invalidar esta posibilidad (Gorrochategui 2006, 125) ¿Podría por tanto ser bolśkan la continuadora de sesars que emite cuando esta ha dejado de hacerlo? Desde luego los denarios oscenses son similares a los de ésta (Collantes 1997, 344). Más arriesgado sería suponer que se trata de la misma localidad con doble nom- bre, el del étnico y el de la civitas, pues la tendencia general es ubicarla en la oscense Sesa, al sudeste de la capital, aunque sin otro argumento que el parecido toponímico. El caso es que cuando emite bolśkan quizás las regiones habían dejado de tener su función, y desde luego se conviene que Osca era ilergete, pero no había perdido el recuerdo de su anterior pertenencia como muestra el texto de Plinio del que luego trataremos. Además de las dos cecas mencionadas, los suesetanos contaron con una tercera, sekia, identificada con Ejea de los Caballeros, que emite en la segunda mitad del s. II.

baŕśkunes o baśkunes.-Evidentemente fuera del área ibérica, como decíamos, es la lectura que presentan monedas, en nominativo (Gorrochategui 2006, 125), datadas en la primera parte del s. II y la primera del i que se han puesto en relación con el pueblo de los vascones (Velaza 1995, 210), aunque también se ha sostenido la imposibilidad de ello al considerarse baŕśkunes/baśkunes nombre indoeuropeo, de raíz celta (opinión de J. Untermann; Gorrochategui 1995, 200; Amela 2000, 18). En cualquier caso, sea o no vascona, se trataría de otra ceca con doble nombre, por cuanto las monedas citadas presentan a la vez las leyendas benkota y bentian, apareciendo ambos a la vez en determinados ejemplares y la primera sólo en otros con la leyenda baŕśkunes/baśkunes, por lo que se ha propuesto al último como etnónimo y a benkota como nombre de la ciudad (Fatás 1989, 385, 393; Id. 1993a, 224-225; Id. 1993b, 290; Sayas 1996, 70). En cuanto a bentian, se ha considerado otro etnónimo, desconocido por las fuentes. A. Domínguez (1997, 141-142) considera que benkota es el nombre de la ciudad que acuña monedas indistintamente para los baŕśkunes/baśkunes y para los bentianos.

Sea como fuere, por el hecho de emitir plata, además de bronce, nos encontramos ante una capital regional y cuadraría más con su atribución a los vascones que a cualquier otro de los populi conocidos, lo que parece certificar la abundancia de hallazgos en Navarra, donde se sitúa el mismo. La ceca se suele ubicar en la actual Pamplona (Domínguez 1997, 143; Tovar 1989, T-30), en virtud de los hallazgos y sobre todo de tratarse de la principal ciudad de los vascones que habría sido rebautizada en el s. I como Pompaelo, justo cuando la ceca deja de emitir. La ubicación no es unánimemente aceptada por considerar poco contundentes los argumentos a favor (García-Bellido \& Blázquez 2001, 55). Se ha propuesto hacerlo también en Sangüesa-Rocaforte, en el extremos del territorio vascón, identificándola con la Baskunsa que menciona, en noticias referidas a 924, Ibn 
Hayyan (Canto 1997, 65) en base a su similitud toponímica. Lo que parece menos claro es que Pamplona hubiera sido la ceca de olkairun que conocemos por unas pocas monedas de la segunda mitad del s. II (Perex 1986, 186).

Así pues, si correspondiera a la antecesora de Pamplona, el pacto entre Pompeyo y los vascones implicaría la sustitución de la denominación benkota por Pompeilun-Pompaelo. La arqueología nos muestra la ocupación del solar pamplonés desde fines de la Edad del Bronce, aunque no alcanza un desarrollo urbanístico importante hasta, precisamente, época de Sertorio y Pompeyo (Mezquiriz 1978, 2930; Amela 2000, 17), motivo no suficiente para negar la presencia de una ceca al menos ya centenaria en ese momento.

\section{LAS REGIONES DE PLINIO Y LA GEOGRAFÍA DE PTOLOMEO}

El ocuparnos aquí, una vez más, de las regiones que Plinio menciona en su descripción de Hispania es por el hecho de que las que corresponden al nordeste peninsular coinciden, casi en su totalidad, con los nombres de étnicos que aparecen en las monedas del s. II: «Regio Ilergaonum, Hiberus amnis, navigabili commercio dives, ortus in Cantabris haut procul oppido Iuliobriga per CCCCL p. fluens, navium per CCLX a Vareia oppido capax, quem propter universam Hispaniam Graeci appellavare Hiberiam; regio Cessetania, flumen Subi, colonia Tarracon, Scipionum opus sicut Cartago Poenorum; regio Ilergetum, oppidum Subur, flumen Rubricatum, a quo Laeetani et Indigetes. Post eos quo dicetur ordine intus recedentes radice Pyrenaei Ausetani [Fitani], Iacetani perque Pyrenaeum Ceretani; dein Vascones.» (n.h. 3, 4, 21-22), y más adelante, aparte de referirse a pueblos citados en el párrafo anterior, cuando trata de los conventus, al hacerlo al Caesaraugustanus, entre los populi que a el pertenecían dice que Caesaraugusta se halla en la regionis Edetaniae y que los oscenses en la regionis Suessetaniae o Uessetaniae (III, 4, 24). De hecho precedidas por la palabra regio aparecen Cessetania, Ilergaonum, Ilergetum, Sedetania y Suessetania.

Es evidente que la región Cesetana se puede relacionar con la ceca de kese, las de los ilergaones o de los ilergetes — problema que ya hemos visto-, con la de iltiŕke, a los layetanos con la de laieśken, a los ausetanos con la de auśesken, a los indigetes con la de untikesken, a los vascones, con dudas, con la de baŕśkunes/baśkunes, a la región de los sedeta- nos - así es como hay que interpretar los edetani aquí mencionados como sedetani tras el ya veterano estudio de G. Fatás - con la de sedeis, y a la suesetana posiblemente con sesars. Nos restan los pirenaicos jacetanos o lacetanos y los ceretanos sobre los que volveré más adelante.

Recordemos que no es la primera vez que las regiones nos aparecen citadas, pues Livio menciona la regio Ilergaonum et Contestanorum (fr. Lib. 91) (Pérez Vilatela 1988, 11), la primera abarcando territorios hasta pleno centro del País Valenciano, en sucesos de las guerras sertorianas de 77-76, pero se trata de una cita puntual que en ese caso es posible que se refiera sólo a una indicación geográfica, una amplia zona determinada donde ubicar los sucesos.

Antes que otra cosa es preciso preguntarnos sobre qué sentido tienen las regiones en Plinio y, sobre todo, cómo ponerlas en relación con una situación dos siglos anterior al ilustre escritor en el nordeste peninsular. Desde luego si como se ha apuntado reflejan una realidad de mediados del s. II, las regiones cuadrarían con una posible organización territorial en los momentos en que se emitieron las monedas y se basarían para ella en una realidad indígena - los populi- pues, después de todo, Roma desde los primeros tiempos de su presencia tuvo una clara comprensión de las realidades variopintas de Hispania y, más concretamente, de aquellos componentes institucionales que mejor podían amoldarse a sus esquemas organizativos (Rodríguez Neila 1998, 101).

Sorprende que Plinio se refiera en el mismo texto a regiones y a conventus iuridici cuando se conviene que los segundos sustituyeron a las primeras quizás desde época augustea años antes del cambio de era (Ozcáriz 2006, 51), bien que en menor número, y englobando cada uno a diversos populi. La pregunta es si las regiones que menciona tuvieron alguna vez un sentido más allá del puramente geográfico. Precisamente que no tuvo otro que este último suele ser la opinión mayoritaria, sobre todo cuando vemos que el mismo autor menciona a la regio Cantabrorum y a la regio Asturum (IV, 34, 111) que, por razones evidentes de cronología no pueden situarse en el conjunto de las que menciona para el Mediterráneo, la cuenca del Guadalquivir y el valle medio del Ebro. Simplemente no pudieron ser regiones republicanas. Si exceptuamos estas dos polémicas, todas se circunscriben exclusivamente al área ibérica: aparte de las que nos afectan del nordeste, las Bastitania, Contestania y Edetania, las tres con una territorialidad mucho más amplia, son las otras mencionadas.

E. Albertini, en su clásico estudio sobre las di- 


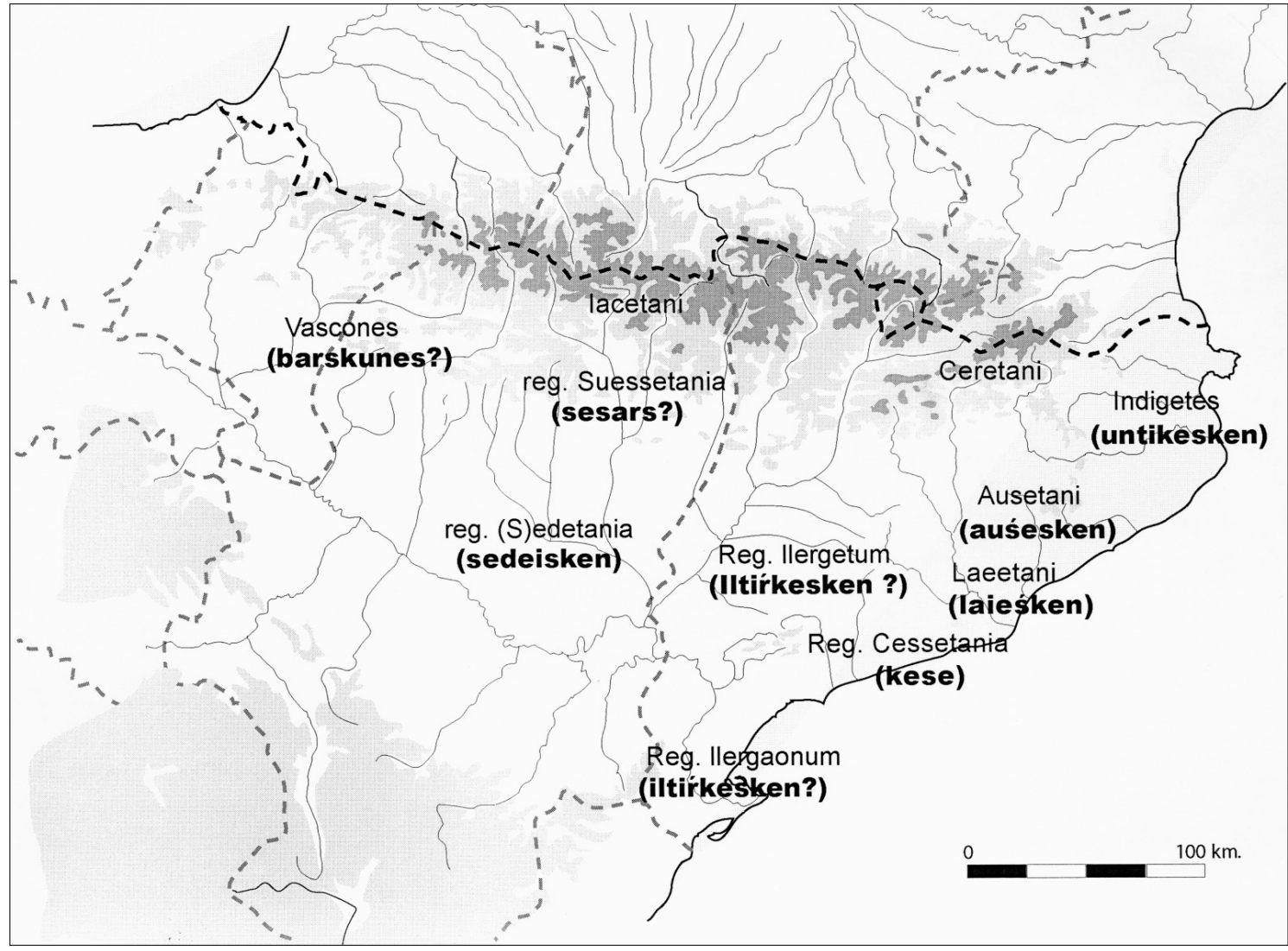

Fig. 2. Regiones y populi mencionados por Plinio en el s. I d.C. y cecas del s. II a.C. con leyenda relacionada con ellos.

visiones administrativas hispanas, creyó que las regiones de Plinio tenían una función militar y fiscal, sobre lo que volvió R.C. Knapp indicando que ello ocurrió exclusivamente en las zonas romanizadas de temprana conquista a diferencia de las posteriores que se estructuraron en populi, haciendo hincapié sin embargo que tenían un criterio más geográfico que étnico (Knapp 1977, 79) aunque llevaran el nombre del pueblo más importante de cada zona. Otros autores siguieron posteriormente esta postura, pero lo cierto es que ignoramos su función real y si tuvieron en realidad alguna práctica (Untermann 1992, 26). Es verdad que parece apoyar su simple contenido geográfico el estudio reciente de la regio Edetana, sobre todo a base de su realidad arqueológica, para la que se concluye que todo parece indicar que carece de todo sentido político (Mata 2001, 264) que es ejercido por lo menos por tres ciudades en su territorio - mucho más extenso que las del nordeste por otra parte-, siendo además sus límites imprecisos y tampoco queda clara la homogeneidad de rasgos culturales propios a través de la arqueología.
No obstante es posible que el nombre que en principio designaba sólo el territorium de una civitas importante en época ibérica, desde el s. II lo haga a uno mayor - por primacía, influencia, pactos o absorción- que pudo ser aprovechado por Roma en su primera organización territorial. Similar conclusión a la edetana se ha propuesto para la contestana (Grau 2005), suponiendo que los más antiguos pueblos que tendrían características comunes se fragmentaron en diversas civitates que, antes situaciones determinadas, se unirían en coaliciones bajo la primacía de una de ellas, reapareciendo en alguna manera el antiguo étnico o sus lazos de identidad. Es verdad que la Segunda guerra púnica con su política de alianzas indígenas, facilitara la comprensión de algo común entre ellos a los ojos romanos. Pero ni los edetanos ni los contestanos contaron con moneda con el nombre del étnico que da a su vez nombre a la región, ni ningún otro documento ni ninguna otra fuente escrita aparte de Plinio se refiere a ellas. Esto último es extensivo a todas las demás regiones. Parece en principio cierto que la voz regio tiene en Plinio 
un carácter no unívoco pues la utiliza refiriéndose a étnicos, a veces a una zona geográfica e incluso a veces a zonas donde no existe un étnico que se pueda vincular con la misma (Capalvo 1986, 56-57; Fatás 1987) y por ello no resulta claro que tuvieran carácter administrativo. Sin embargo al norte del Ebro contamos con monedas que nos hacen pensar a que las regiones fueron algo más que una designación geográfica, aunque ignoremos su concreta finalidad, siendo lícito preguntarse si no se trataba de la primera organización territorial administrativa y también fiscal. Es interesante sin embargo la observación de J.M. Roldán (1983, 169), referida a las regiones de Plinio, de que cada una contaba con un centro de acuñación en plata, lo cual en el s. II no es cierto: ni sedetanos, ni layetanos ni ilercavones lo tuvieron.

El problema es que, como antes decíamos, ninguna otra fuente aparte de Plinio las menciona - como por lo demás tampoco los conventus - y, evidentemente, en el último cuarto del s. I d.C., es decir en su época, no tendrían ninguna función territorial desde la municipalización augustea. Por qué Plinio se refiere a ellas no esta claro, máxime cuando el mismo estuvo en Hispania, en la Citerior como procurator, precisamente mientras trabajaba en su obra y hay que suponer que la conocería bien. Se acepta que sus fuentes principales, aparte de su experiencia personal, fueron el Orbis pictus de Agripa concluido en el 14, el llamado Breviario de Augusto y las informaciones de Varrón escritas en el meridiano del s. I cuando en su calidad de oficial pompeyano, conocía asimismo bien la península. En cualquier caso se trata de obras que, en mi opinión, corresponden a un momento en que las regiones no tenían razón de ser aunque en el caso de Varrón no se hubiera producido aún el proceso de municipalización. Seguramente se conservaba el recuerdo de las mismas lo que sugiere un notable enraizamiento y una singular importancia en su momento. El que no se mencionen en las fuentes republicanas puede explicarse tanto por la escasez de las mismas en los momentos en que pudieron estar activas como al propio carácter de las mismas, centradas entonces en las guerras contra los celtíberos y lusitanos, no ocupándose apenas de las zonas donde el poder de Roma se había afianzado. Al menos hemos de considerar posible que Plinio utilizara, en su erudición y su ingente curiosidad, otras fuentes desaparecidas. Curiosamente no lo hizo con la Geografía de Estrabón, completada en el año 7, que parece no haber conocido (Howatson 1991, 341). El geógrafo griego menciona a diversas etnias, no regiones, entre ellas, en la costa, a los indicetes di- vididos en cuatro partes, entre ellos los leetanos y lartolaietes — sólo por él mencionados, quizás los dos se refieren a los layetanos-y «otras tribus» hasta Emporion $(4,8) \mathrm{y}$, en el interior, jacetanos, ilergetes, vascones y cerretanos $(3,4,10-11)$. Salvo el caso de los lartolaietes y con la ausencia de los ausetanos y los ilercaones, vienen a coincidir con las regiones plinianas. Es evidente que tampoco tenían sentido los étnicos en la división territorial de época de Estrabón. La otra fuente geográfica, la que representa la obra de Mela, escrita en tiempos de Claudio, no menciona a étnicos, solo provincias y ciudades, lo que muestra, a pesar de la brevedad de su texto - y ello es algo desde luego a tener en cuenta en cuanto a escasez de nombres de ciudades-, unas provincias hispanas que en este aspecto no se diferencian en nada de cualquiera otras del Imperio plenamente romanizadas. Sin embargo en el s. I d.C. no se había perdido el recuerdo de los antiguos étnicos que no tenían ninguna plasmación práctica en la organización territorial, y ello es extensivo al siguiente como muestra la Geographías Hyphégesis de Claudio Ptolomeo. Por supuesto, aún más claro que Plinio por cuanto es cronológicamente posterior, las etnias que menciona no tendrían ninguna operatividad política ni otras claras en su momento (Untermann 1992, 29). En realidad en la obra de Ptolomeo se mezclan diversas fuentes gestándose una realidad anacrónica (Gómez Fraile 1997, 188, 195).

Ptolomeo que como es sabido relaciona a las ciudades precedidas del étnico a que pertenecen, cita en la costa a ilercaones, cosetanos, layetanos, indigetes $(2,6,16-19)$, y en el interior, edetanos - mezcla a éstos con sedetanos a los que no nombra- y luego de nuevo ilercaones, vascones, ilergetes, ceretanos, ausetanos, castellanos, iacetanos —se ha querido leer lacetanos por la inclusión en ella de Iessos, actual Guissona-, indigetes y layetanos (62-72). $\mathrm{Si}$ exceptuamos el problema jacetanos-lacetanos-layetanos que luego trataremos, la ausencia de suesetanos, y la extraña mención de castellanos, no citados por ninguna otra fuente y ninguna de las ciudades que les atribuye localizadas, el panorama coincide con las regiones plinianas, aunque se ha sostenido que, en general, las etnias de Ptolomeo son incompatibles con las últimas (Pérez Vilatela 1988, 13). Los castellani habría que situarlos entre layetanos, lacetanos y ausetanos, quizás en el Montseny y la Selva (TIR K/J 31, 58). Por lo demás, las numerosas contradicciones e irregularidades que se han señalado en la obra de Ptolomeo hacen que se hayan de manejar sus datos con mucha cautela, hasta el punto que si es posible, conviene utilizar otras 
fuentes y darles mayor credibilidad (Jordán 2006, 84). Como fuere, F. Burillo cree que Ptolomeo reflejaría en su obra datos que podían estar en uso en la segunda mitad del s. I y serían las mismas que utilizaron Estrabón o Plinio, y que se trataría de la distribución resultante de los cambios sufridos tras los enfrentamientos bélicos del s. I (Burillo 1998, 14, 330; Id. 2001, 197). Por mi parte me inclino a creer que, en atención a los datos numismáticos, ello sucedió antes, como veremos.

Volviendo a Plinio, hay otro problema interesante basado en el orden en que cita las diversas regiones siguiendo la costa, y es la mención de la ilergete entre la cesetana y la layetana, lo que ha dado origen a suponer unos ilergetes costeros diferenciados de los del interior en torno al Segre, a los que por cierto no mencionaría. Este último hecho creo que es suficiente para suponer que se trata de éstos y no hay que pensar en dos pueblos con el mismo nombre como se propuso para los ausetanos, pues si lo hace es porque se trata del más importe de los pueblos del interior y desde luego limítrofe con los cesetanos-, como queda claro en las fuentes alusivas a la Segunda guerra púnica. Sin embargo, considerando que Plinio se refiere a los ilerdenses como surdaones (n.h. $3,4,24)$-es un problema no resuelto el que se esconde tras esta única y extraña mención-, se ha propuesto la presencia de unos ilergetes costeros, donde además se situaría la Athanagia que Livio mencionada como capital ilergeta en 218 (21, 61, 67) y que éstos serían los ileragautai de Hecateo en el s. VI (Jacob 1987-1988, 137), a los cuales pertenecería, siguiendo a Plinio, la localidad de Subur citada también por Mela $(2,90)$ al norte de Barcino y como cosetana o cesetana por Ptolomeo (II, 6, 17) y de localización desconocida si bien costera (TIR $\mathrm{K} / \mathrm{J}-31$ ). Esta postura tuvo una cierta fortuna hace unas décadas (Iniesta 1989, 351-352, 357), pero en general hoy no es aceptada, al menos con el mismo éxito que el otro doblete anteriormente tratado de los ausetanos.

$\mathrm{Si}$ en el caso de las regiones edetana y contestana no era factible, en las del nordeste ha querido verse una cierta posibilidad de identificación arqueológica, al menos en el caso de cesetanos y layetanos (Arrayás 2006, 216 ss.) gracias a los intensos trabajos realizados en las comarcas del Alt y del Baix Penedés y del Garraf (diversos de J. Sanmartí y J. Santacana) y al estudio de N. Rafel (1979) de la circulación monetaria en el Penedés donde la mayoría de la ceca de kese es más que manifiesta, mientras la de laieśken lo es en la vecina zona norte del Garraf. Precisamente allí habría que situar el límite entre las dos en la franja costera, en la que por cierto nada hay que pueda hacer pensar en una ilergete entre ambas. Algo más al interior el limite entre ambas vendría a estar marcado en los términos de Martorell y Castellbisbal, separados por el conocido puente del Diable que aún hoy sirve de separación a comarcas, la del Penedés por un lado y de las del Vallés y Baix Llobregat por otro y que, en el Alto imperio, señalaba los límites de Tarraco de los de Barcino (Gurt-Rodà 2005, 159). Por mi parte más al interior creo que la separación de la Cesetana de la Ilergete debía coincidir, en sus líneas esenciales, con la que hubo entre las civitates altoimperiales de Tarraco e Ilerda entre las que no mediaba ninguna otra colonia ni municipio conocido. Que no hubiera otra ciudad entre ambas no sería extraño a pesar de la distancia que separa sus núcleos urbanos, pues por ejemplo la Lex riui Hiberiensi, hallada en 1993, muestra como el territorium de Caesaraugusta llegaba hasta la actual Gallur, a unos 50 kms. de Zaragoza (Beltrán 2005, 129-139) y hay que suponer otro tanto, al menos, hacia el este. Los territorios de Tarraco e Ilerda debieron ser singularmente extensos.

Las regiones en el nordeste, si alguna vez tuvieron una función con este u otro nombre creo que no pudo ser sino en el s. II, en un momento impreciso del mismo pero que creo muy posible tras la «pacificación» catoniana o poco después, tal como muestra la cronología de las monedas con nombre de étnico que, salvo kese e iltiŕke, desaparecen a partir del meridiano del s. II, seguramente después pero antes de su final. Por ello no creo que fueran sustituidas por los cambios que comportó la nueva organización augustea, sino que se produjo varios decenios antes de la misma. Una nueva organización nos es sugerida por la arqueología entre fines del s. II y el primer tercio del s. I a.C. en que tienen lugar la fundación y «refundación» de diversas ciudades -Aeso, Iesso, Ilerda, Gerunda, Iluro, Baetulo...- ortodoxamente romanas en su morfología, pero sin status romano o latino como muestran sus monedas en caracteres indígenas, habitadas por indígenas en parte ya romanizados en sus elites - véase los tres caballeros ilerdenses con nombres latinos de la turma Salluitanay que creo que formaban parte de un plan global que desde Liguria organizaba el territorio a la romana hasta los límites de la recién domeñada Celtiberia donde aún fueron importantes las guerras hasta inicios del s. I (Pérez Almoguera 1994). De hecho la municipalización cesariano-augustea no hacía sino oficializar una realidad ya de facto que antes habría sustituido a las regiones. 


\section{LAS AUSENCIAS. EL PROBLEMA DE LOS CERETANI Y IACETANI/LACETANI}

Ya hemos visto cómo no consta moneda étnica para los ceretani así como el problema que plantean los iacetani por la semejanza de su nombre con los lacetani, de los que tampoco consta moneda, y con los laeetani. Citados los ceretani por Plinio (n.h. 3, 22, 23), se trataría del único de los pueblos importantes - aunque sin duda menos que sus vecinosque, se conviene, careció de moneda. Se trata de un pueblo pirenaico cuyo nombre ha perdurado en la actual Cerdanya y que posiblemente tuvo organización municipal en Iulia Libica, la actual Llivia, pero del que no consta ninguna ciudad más. Citados como ceretes por Avieno (ora 550), lo será después también por Estrabón $(3,4,11)$ y Ptolomeo (geog. 2, 6, 68), amén de Silio Itálico (3, 357), Marcial $(13,54)$ y Dión Casio $(48,41,1)$. La iberización de su territorio fue tardía y limitada, no documentándose hasta el último tercio del s. II (Olesti-Mercadal 2005). No obstante se considera iberos a los ceretani (Untermann 1992, 31), apareciendo en antropónimos como el kules-kere de Pech-Maho o el bilos-kere de Binéfar.

Con todo a partir de esa época, y por encuadrarse en su territorio el nacimiento del Segre constituyendo un camino natural entre Narbo e Ilerda quizás estuviera englobado en la órbita de la moneda ilergeta, y ello quizás pudiera ser extensivo a sus vecinos lacetanos. Sin embargo se ha apuntado la posibilidad de que hubiera una ceca temprana, de la que se conocen tres dracmas en que ha querido leer kerir aunque la lectura plantea dudas (Collantes 1997, 236) que lógicamente se habrían emitido durante la Segunda guerra púnica o época inmediata. L. Villaronga (1994a, 40, núm. 26) propone sin embargo la lectura erur, lo que invalidaría la adscripción. No podemos encontrar una explicación clara de esta singularización con respecto a sus vecinos en lo que hace a la ausencia de moneda. ¿Por su ubicación pirenaica?, ¿por contar que sepamos con una sola ciudad como menciona Ptolomeo y no fuera preciso crear una región?, ¿por estar relacionados los ceretes con los ausoceretes que menciona Avieno y en realidad fue su capital monetaria auśesken? Creo que la explicación más plausible es que, como indicábamos, la iberización se produce en un momento en que desaparecen -o han desaparecido- las leyendas con nombre étnico.

Los lacetani plantean otro problema diferente, derivado de la similitud, casi homófona, con los iacetani y también con los laietani, lo que se considera que ha proporcionado confusiones ya en las fuentes antiguas. Por lo menos en un caso (Livio, 21, 60, 3) hay motivos para suponer que se trata de layetanos por situar los acontecimientos en la región costera (Untermann 1992, 21). Se ha llegado incluso a negar hace un tiempo la existencia de los lacetanos y proponer que las fuentes se refieren a uno u otro de los otros dos pueblos mencionados, postura retomada con nuevos argumentos recientemente (Broch 2004), pero también ha habido quien negaba la condición de populus a los iacetani y no a estos por la misma razón (Beltrán 1999 2001, 70-71; Id. 2006, 225), tratándose la última sólo de una comunidad urbana que además no parece vascona como a veces se ha sostenido, aunque tampoco ibera ni celta, que emite sólo a fines del s. II, si no después, y el primer tercio del I (García-Bellido \& Blázquez 2001, 169). Según ello las alusiones al pretendido pueblo pirenaico lo serían en realidad a los lacetanos, sometidos en 195. Los lacetanos no emitieron monedas en el s. II no sólo con el nombre del populus sino con el de ninguna de las localidades que les atribuye Ptolomeo, pero es que tampoco constan en ningún otro documento epigráfico.

Se suele convenir, aunque no con unanimidad, que las citas de Livio $(21,23,2 ; 21,61,8 ; 28,24,4 ; 34$, $20,1-2 ; 34,20,6)$ alusivas a sucesos sobre todo de 195, se refieren a los lacetanos, e igualmente las de Plutarco (cat. ma. 11,2) — aunque también se duday la de Salustio (epist. Pomp. 5), pero menos claro resulta la de Plinio (nat. 3, 22) - de primordial importancia en nuestro caso como hemos visto- en que no esta claro si se refiere a estos o a los iacetani. Ptolomeo menciona a los jacetanos, aunque los defensores de la existencia de lacetanos lo consideran un error (Sanmartí-Santacana 2005, 37) por las ciudades que este último les adscribe: Lesa, Udura, Ascerris, Setelsis, Telobis, Ceresus, Bacasis, Iessos, Anabis y Cinna. Demasiadas ciudades en principio, prácticamente desconocidas a excepción de Iessos que difícilmente se podría adscribir a los jacetanos por corresponder a una localidad, Guissona, que se encuentra en la región que tradicionalmente se asigna a los lacetanos. El alejandrino sitúa a estos precisamente al este de los ilergetes, pero no hay que olvidar que también el nordeste menciona a unos desconocidos castellanos. Por lo demás, a la ciudad de Iacca la sitúa entre las vasconas. El problema no es fácil de dilucidar, pero lo cierto es que si existió este pueblo, no emitió moneda con su nombre como los demás, lo que resulta extraño y redundaría de alguna forma en un argumento más, aunque no contundente, para quienes niegan su existencia. 


\section{CONCLUSIÓN}

De cuanto acabamos de ver, puede extraerse el siguiente cuadro en el cual, a través de las regiones y populi que menciona Plinio, se tienen en cuenta todas las cecas del nordeste con nombres relacionados con étnicos, la fecha de su funcionamiento, si se pueden considerar capitales monetarias por su emisión de plata o no, y su otro nombre posible no relacionado con el étnico.

\begin{tabular}{|c|c|c|c|c|}
\hline Regio o populus Plinio & Ceca con etnónimo & Cronología & Plata & Otro nombre \\
\hline $\begin{array}{l}\text { Regio Ilergaonum } \\
\text { Regio Cessetania } \\
\text { Regio Ilergetum } \\
\text { Laeetani } \\
\text { Indigetes } \\
\text { Ausetani } \\
\text { Iacetani (_Lacetani?) } \\
\text { Ceretani } \\
\text { Regionis (S)Edetaniae } \\
\text { Regiones Suessetaniae } \\
\text { Vascones }\end{array}$ & $\begin{array}{l}\text { ¿iltírkesken? } \\
\text { kese } \\
\text { ¿iltírkesken? } \\
\text { laieśken } \\
\text { untikesken } \\
\text { auśesken } \\
\\
\\
\text { seteisken } \\
\text { ¿sesars? } \\
\text { ¿baŕsunes? }\end{array}$ & $\begin{array}{l}\text { Fines S. III-I } \\
\text { Fines s. III-I } \\
\text { Fines S. III-I } \\
\text { s. II } \\
\text { S. II } \\
\text { s. II }\end{array}$ & $\begin{array}{l}\text { No } \\
\mathrm{Si} \\
\text { No } \\
\text { No } \\
\text { No } \\
\mathrm{Si}\end{array}$ & $\begin{array}{l}\text { ¿Hibera Dertosa? } \\
\text { taŕakon } \\
\text { ¿baŕkeno? } \\
\text { Emporion }\end{array}$ \\
\hline
\end{tabular}

Del cuadro se infiere que durante el s. II —en el caso especial de kese y en el dudoso de baŕśkunes hasta el siguiente-, en el nordeste peninsular se emiten monedas con nombre de étnico que coinciden con las regiones y los populi que en el s. I d.C. menciona Plinio, en un momento en que ya no tendrían ningún sentido práctico dado que la municipalización era un hecho desde tiempos de Augusto y, entre las ciudades y las provincias, los conventus iuridici, también conocidos por Plinio, vendrían a ser la circunscripción intermedia entre ambas, por lo menos en el aspecto judicial. Los conventus iuridici por otra parte tuvieron una extensión territorial superior a las regiones y no sabemos si las sustituyeron dada la diferencia cronológica que separa las monedas que pudieran reflejar a las mismas y la mención en que por primera vez $-\mathrm{y}$ única en realidad- se menciona a los últimos. Cabe pues pensar que en el s. II una especie de regiones -ignoramos si esta fue su designación - con el nombre de étnicos tuvieron alguna función relacionada con la organización del territorio, al menos en el nordeste peninsular, bien que ignoremos concretamente cual por falta de datos, sin duda la primera tras la asunción de la conquista, que pudo tener lugar tras la pacificación de Catón o a partir de 180 o como mucho mediados - no creo en una fecha tan tardía como 133 también propuesta-, de la que nada nos informan las fuentes escritas o epigráficas. Esta primera organización desaparecería, si atendemos de nuevo a la numismática, a fines del mismo mejor que a inicios del I, cuando se comprueban nuevas fundaciones o refundaciones «a la romana» pero aún básicamente habitadas por indígenas, que nos muestra la arqueología y la numismática. Es significativo que ya en 90 a.C. el conocido Bronce de Ascoli o Turma Salluitana nos mencione a los caballeros indígenas que reciben la ciudadanía por su ciudad de origen sin la menor indicación de tribu o pueblo «que ya no jugaba ningún papel político a inicios del último siglo a.C.» (Untermann 1992, 24).

En cuanto a las cecas con nombre étnico cuya lectura aparece con el genitivo - $(e)$ sken, que es exclusivo en el nordeste peninsular de etnónimos, menos otobeśken que por lo demás pudiera ser edetana, podemos suponer su final a fines del II coincidiendo con la nueva organización territorial mencionada que se plasma en los primeros tiempos del siguiente. Dos sin embargo plantean dudas. Una de ellas es iltirkesken aunque se supone que h. 90 ya habría emitido casi toda su producción (Campo 2005, 73-79). Quizás, visto lo que ocurre con las demás y teniendo en cuenta la incertidumbre con que nos movemos en la cronología numismática, es posible que precisamente antes, quizás no mucho, de esa fecha también dejara de hacerlo. La otra es untikesken, que se acepta su funcionamiento en la primera mitad del I. De ser así, podría explicarse por tratarse de Emporion - que a su vez emite plata quizás hasta inicios del s. I-, caso especial al ser la ciudad aliada desde los primeros momentos de presencia romana que continuara emitiendo hasta la fusión municipal de las dos comunidades. El caso singular queda reflejado en el hecho de que en algunas monedas figuren magistrados con nombres latinos iberizados en la segunda mitad del s. II. 
Distinto es lo que sucede con kese, que aparece siempre en nominativo, y tiene además, como corresponde a la principal base romana provincial, una longevidad muy superior a las otras, abarcando desde fines del s. III con sus dracmas y divisores hasta quizá en torno al 70. El problema de lacetani y cerretani, sin cecas con nombre étnico conocido - y en realidad de ninguna otra localidad atribuida a los mismos en el s. II-, aparece muy relacionado en el primero por su confusión con iacetani y laietani, que ha llevado incluso a proponer su no existencia. Sin ser tan drásticos, su posible escasa entidad pudiera ser una causa. Los cerretani fueron un pueblo montañés iberizado tardíamente sin poblaciones de importancia y con escasa demografía. En cuanto a sesars y baŕśkunes, si es que se refieren a populi, se comportan de manera distinta, quizás porque la primera si se encontraba en el área ibérica, era en su linde y la segunda simplemente no lo hacía y posiblemente llegara en sus emisiones hasta las Guerras Sertorianas.

Varias de estas cecas fueron sin duda auténticas capitales monetarias: las que acuñaron plata. Fueron kese, auśesken, sesars y baŕśkunes. En principio pudiera resultar extraño que no lo hiciera iltiŕkesken, teniendo en cuenta que había emitido dracmas con anterioridad. Si se refiere a los ilergetes, el papel de emisora monetaria fue iltiŕta, ceca prolífica sólo comparable a kese en cuanto a importancia y número de emisiones que también lo hizo en plata. En cuanto a los indiketes, untikesken sólo acuñó bronces porque la plata la acuñaba Emporion.

La otra cuestión que planteábamos es si las que emiten con nombre étnico tienen a su vez otro nombre. De entrada hay un caso que suele aceptarse: kese es la misma localidad que taŕakon que emite también dracmas con ese nombre a fines del s. III, pero prevalecerá desde el s. II el del étnico. En cualquier caso no deja de llamar la atención que en un determinado momento, aunque breve, emitiera con los dos nombres. Al sur del Ebro, y por tanto fuera del área que estudiamos, contamos con el conocido caso de arse-Saguntum aunque las fuentes nada nos dicen de los arsetanos como populus y sólo emitió con ese nombre. Otro caso es el de untikesken-Emporion, pero aquí se trata de una ciudad doble y el indígena no aparece hasta el s. II. Como fuera, es posible que el caso de kese-taŕakon funcionara bien para los intereses romanos y fueran el precedente para que en el s. II aparecieran las otras monedas con nombre étnico, bien que en genitivo. ¿A alguna de estas podemos suponerle otro nombre? Hemos apuntado la posibilidad —nunca más bien dicho- de que laieśken fuera la misma que baŕkeno, pero en los otros casos no tenemos, si cabe, ningún argumento, aunque no sería extraño que lo tuvieran hubieran emitido o no moneda con el mismo. Resta el caso de iltiŕkesken, que por las dracmas hemos de suponer a una localidad llamada iltiŕka nombre que ha de corresponder a ilergetes o ilercavones, siguiendo las normas con que pasa el ibero al latín. No creemos que sea iltiŕta la principal localidad y ceca ilergete, con la que desde fines del III se debió identificar todo el populus lo que puede explicar que la regio no contara con una ceca con nombre étnico. Parece en principio más lógico atribuirla a los ilercavones, con lo que habría otra regio con monedas con nombre étnico que a su vez sería el de la ciudad, quizás llamada también Hibera o Dertosa, pero tampoco podemos en absoluto aseverarlo. Al menos la distribución de hallazgos de sus monedas no cuadra.

Cuales eran los fines de Roma al promocionar la emisión de monedas con nombre étnico no resulta tampoco claro, pues no en todos los casos es fácil admitir que a través de documentos monetarios los indígenas se identificaran con una localidad aunque llevara el nombre tribal, si bien su sentido de pertenencia a un pueblo no se habría perdido a pesar de que su marco era ya la ciudad y casi todos ellos contaban con más de una. Si el fin era ese, no afectaría más que a unas elites, pues no está claro que la moneda se generalizara aún en el s. II para unos cotidiano y mucho menos pensar que, salvo una minoría, nos encontraramos ante sociedades alfabetizadas. ¿Se trataba de un fin recaudatorio basado en una organización territorial que a su vez se basaba en los principales populi? El hecho de que no todas precisamente acuñaran plata permite, como mínimo, plantear la duda.

\section{BIBLIOGRAFÍA}

ABAD, L.-Bendala, M. (1995): «Urbanismo y ciudad: de las formaciones ibéricas a la consolidación del modelo romano», Actas del XXIII Congreso $\mathrm{Na}$ cional de Arqueología, II, Elche, 11-20.

Abascal, J.M.-Espinosa, U. (1989): La ciudad hispano-romana. Privilegio y poder; Logroño.

Adserías, M. et al. (1993): «L'assentament pre romà de Tarragona», RAP, 3, 177-227.

Aguilar, M. ${ }^{\text {a }}$ A.-ÑACO, T. (1997): «Fiscalidad romana y la aparición de la moneda ibérica. Apuntes para una discusión. II. 195-171 a.C.: algunos textos polémicos», Habis, 28, 71-86.

Alföldy, G., (1991): Tarraco. Forum 8, Tarragona.

Alonso, N. (2000): «Cultivos y producción agrícola en época ibérica», Saguntum, extra 3, 25-46. 
Amela, L. (2000): «Las ciudades fundadas por Pompeyo Magno en Occidente», Polis 12, 7-41.

Arrayas, I. (2006): Morfología histórica del territorio de Tarraco (s. III-I a.C.), Barcelona.

BARberÀ, J.- Dupré, X. (1984): «Els laietans, assaig de síntesi», Fonaments, 4, 31-86.

Beltrán, F. (1984): «El año 218 a.C. Problemas en torno al comienzo de la Segunda guerra púnica en la Península Ibérica», 5 Col.loqui Internacional d'Arqueologia de Puigcerdà, 147-171.

- (1993): «La epigrafía como índice de aculturación en el valle medio del Ebro (s. II a.e.-II d.e.)», en Untermann, J.- Villar, F. (eds.), Lengua y cultura en la Hispania prerromana, Salamanca, 235-272.

- (1995): «La escritura en la frontera. Inscripciones y cultura epigráfica en el valle medio del Ebro», Beltrán, F. (ed.), Roma y el nacimiento de la cultura epigráfica en el Occidente, Zaragoza, 169195.

- (2001): «Hacia un replanteamiento del mapa cultural y étnico del norte de Aragón», en Villar, F. Fernández Alvarez, M.P. (eds.), Religión y culturas prerromanas de Hispania, Salamanca, 61-81.

- (2005): «Nuevas perspectivas sobre el riego en Hispania: la Lex riui Hiberiensis», en Hernández Guerra, L. (ed.), Actas del II Congreso Internacional de Historia Antigua, La Hispania de los Antoninos, Valladolid, 129-139.

- (2006): «El Valle Medio del Ebro durante el periodo republicano: de limes a conventus», Cruz, G.- Le Roux, O.- Moret, P. (eds.), La invención de una geografía de la Península Ibérica I La época republicana, Málaga, 217-240.

- (1996): Los iberos en Aragón, Zaragoza.

Benages, J. (2001), «Les monedes de Tarragona (addenda tercera)», Acta Numismática, 31, págs. 17-30.

Blanch, R.M. et al. (1994): «Un gran magatzem laietà al Mont Jovis: les sitges del port», III Congrés d'Història de Barcelona, Barcelona, 223-228.

Broch, A. (2004), «De l'existència dels lacetans», Pyrenae, 35-2, págs. 7-29.

Burch, J.-Nolla, J.M. (1995): «Gerunda i els ausetans. Una question recurrent», Homenatge a J. Marqués i Casanovas, AIEG, 3, 9-26.

Burillo, F. (1993): «Propuesta de una territorialidad étnica para el Bajo Aragón: los ausetanos del Ebro u ositanos», Kalathos, 20-21, 159-187.

- (1995): «Celtiberia: monedas, ciudades y territorios», La moneda hispánica. Ciudad y Territorio, Anejos AEA, XIV, 161-177.

- (1996): «Sobre la territorialidad de los sedetanos», Homenaje a Purificación Atrian, Teruel, 103-134.
- (1998): Los celtíberos. Etnias y estados, Barcelona.

- (2001): «Etnias y poblamiento en el área ibérica del valle medio del Ebro: sedetanos y edetanos», en Berrocal, L.-Gardes, Ph., Entre celtas e iberos. Las poblaciones protohistóricas de las Galias e Hispania, Madrid, 187-200.

CAMPO, M. (1997): «La moneda griega y su influencia en el contexto indígena», en Alfaro, C. et al., Historia monetaria de la Hispania Antigua, Madrid, 19-49.

- (1998): «Les primeres monedes dels ibers: el cas de les imitacions d'Emporion», II Curs d'Història monetaria d'Hispania. La moneda a la societat ibérica (Barcelona, 26-27 novembre1998), Barcelona.

- (2002): «La producció d’Untikesken i Kese: funció i circulació a la ciutat i al territori», VI Curs d'Història monetaria d'Hispània. Funció i producció de les seques indígenes (Barcelona, 28/29 novembre 2002), Barcelona.

- (2005): «Emissió i circulació monetàries al nordest de la Hispana Citerior al final de la república», IX Curs d'Història monetaria d'Hispania. La moneda al final de la república: entre la tradició $i$ la innovació (Barcelona, 24/25 novembre 2005), Barcelona, 73-93.

Canto, A.M. (1997): «La tierra del toro. Ensayo de identificación de ciudades vasconas», AEspA, 70, 31-70.

Capalvo, A. (1986): «El léxico pliniano sobre Hispania: etnonimia y designación de asentamientos urbanos», Caesaraugusta, 63, 44-67.

Collantes, E. (1995): «Una dracma de imitación del bando cartaginés», La moneda hispánica. Ciudad y Territorio, Anejos AEA, XV, 325-330.

- (1997): Historia de las cecas de Hispania antigua, Madrid.

CRUSAFOnT, M. (1989):»Dos hemiobols inedits de la zona del Segre», Acta Numismática, 19, 53-58.

De Guadan, A.M. (1956): Las leyendas ibéricas en las dracmas de imitación emporitana, Madrid.

De Hoz (1995): «Notas sobre nuevas y viejas leyendas monetales», La moneda hispánica. Ciudad y Territorio, Anejos AEA, XV, 317-324.

De Hoz, J. (1992): «El complejo sufijal -(e)sken de la lengua ibérica», Palaeohispanica, 2, Zaragoza, 159-168.

Diloli, J. (1996): «Hibera Iulia Ilercavonia-Dertosa: 1'assentament ibèric i la implantació de la ciutat romana», BAT, $V, 18,39-68$.

Diloli, J.; Corominas, M.; Arola, R. (2001): «Acuñaciones ibero-romanas en el Bajo Ebro en un 
contexto de cambio de era: la pervivencia del sustrato indígena», Hernández Guerra, L.-Sagredo, E.-Solana, J.M. (eds.), La Península Ibérica hace 2000 años. Actas del I Congreso Internacional de Historia Antigua, Valladolid, 545-551.

Domínguez, A. (1979): Las cecas ibéricas del valle del Ebro, Zaragoza.

- (1997): «Las acuñaciones ibéricas y celtibéricas de la Hispania Citerior», Alfaro, C. et al., Historia monetaria de la Hispania Antigua, Madrid, 116-193.

EspañA, L. (2000): «Las dracmas de la Medusa en el territorio Kesetano del s. III a.C.», Gaceta Numismática, 138, 21-31.

FAtÁs, G. (1973): La Sedetania. Las tierras aragonesas hasta la fundación de Caesaraugusta, Zaragoza.

- (1987): «Apunt sobre el ilergets i llurs terres occidentals», Fonaments, 6 , 11-22.

- (1989): «Los vascones y su territorio», «Iberos y celtas en la cuenca media del Ebro», en Montenegro, A. et al., Historia de España.2. Colonizaciones y formación de los pueblos prerromanos (1200-218 a.C.), Madrid, 376-428.

- (1993a): «Para una etnografía de la cuenca media del Ebro», Paleoetnología de la Península Ibérica, Complutum, 2-3, 223-232.

- (1993b): «los Pirineos meridionales y la conquista romana», Untermann, J.- Villar, F. (eds.), Lengua y cultura en la Hispania prerromana, Salamanca, 289-315.

GARCÉs, I. (2002): «La societat a l’època ibérica», Sala d'Arqueologia, Catàleg, Quaderns de la Sala d'Arqueologia, 2, I.E.I., Lleida, 181-190.

García-Bellido, M.P. (1993a): «El proceso de monetización en el levante y sur hispánico durante la Segunda guerra púnica», Untermann, J.-Villar, F. (eds.), Lengua y cultura en la Hispania prerromana, Salamanca, 317-347.

- (1993 b): «Origen y función del denario ibérico», Sprachen und Schriften des antiken Mittelmeerraums. Festschrift für Jürgen Untermann zum 65. Geburtstag, Innsbruck, 97--121.

- (1998): «Sobre la moneda de los iberos», Revista de Estudios Ibéricos, 3, 109-126.

- (2001): «Numismática y étnias: viejas y nuevas perspectivas», Villar, F.-Fernández Álvarez, M.P., Religión, lengua y cultura prerromanas de Hispania, Salamanca, 135-168.

García-Bellido, M.P.; Blázquez, C. (2001): Diccionario de cecas y pueblos hispánicos, Madrid.

García-Bellido, M.P.; Ripollés, P.P. (1998): «La moneda ibérica: prestigio y espacio económico de los iberos», VV.AA., Los iberos principes de occidente, Barcelona, 205-215.

García Garrido, M.; Montañés, J. (1989): «Divisores de plata inéditos o poco conocidos de la Hispania Antigua», Acta Numismática, 19, 45-52.

García RiazA, E. (2002): «Dinero y moneda en la Hispania indígena: la mirada de las fuentes literarias», VI curs d'Història monetaria d'Hispania. Funció i producció de les seques indígenes (28/ 29 novembre 2002), Barcelona, 9-30.

Genera, M. (1993): «Dertosa, una ciutat romana», La ciudad en el mundo romano, XIV Congreso Int. de Arqueología Clásica, pre-actas II, Tarragona, 140.

Gómez Fraile, J.M. ${ }^{\text {a }}$ (1997): «La geografia de la Hispania Citerior en C. Tolomeo: análisis de sus elementos descriptivos y aproximación a su proceso de elaboración», Polis, 9, 183-247.

Gorrochategui, J. (1995): «Los Pirineos entre Galia e Hispania: las lenguas», Veleia, 12, 181-234.

- (2006): «Onomástica vascónica y aquitana: elementos para el conocimiento de la Historia Antigua de Navarra», VV.AA., Navarra en la Antigüedad, propuesta de actualización, Pamplona, 111-134.

Gracia, F. (2006): Roma, Cartago, Iberos y celtíberos. Las grandes guerras en la península Ibéri$c a, 2^{\mathrm{a}}$ reimpresión, Barcelona.

Grau, I. (2005): «Espacios étnicos y políticos en el área oriental de Iberia», Complutum, 16, 105-123.

Guitart, J.; Pera, J. (eds.) (2004): Iesso I. Miscel lania Arqueológica, Barcelona-Guissona.

GurT, J.M.; RodÀ, I. (2005), «El Pont del Diable. El monumento romano dentro de la política territorial augustea», AEspA, 78, 147-165.

Howatson, M.C. (1991): «Plinio.1. Plinio el Viejo», Diccionario de la literatura clásica, Madrid, 341.

INIESTA, A. (1989): «Pueblos prerromanos de Levante, Cataluña y Baleares», Montenegro, A. et al., Historia de España 2. Colonizaciones y formación de los pueblos prerromanos (1200-218 a.C.), Madrid (reimp. 1998), 346-375.

JАСOB, P. (1987-1988): «Un doublet dans la geographie livienne de 1'Espagne antique: les ausetans de 1'Ebre», Kalathos, 7-8, 135-147.

JÁrRega, R. (2004): «Tarraco Scipionum opus. ¿Escipión Emiliano, fundador de Tarraco?», Butlletí Arqueològic, 26, 23-65.

JoRDÁn, A.A. (2006): «La expansión vascónica en época republicana: reflexiones en torno a los límites geográficos de los vascones», VV.AA., Navarra en la Antigüedad, propuesta de actualización, Pamplona, 81-109. 
KeAy, S.J. (1996): «La romanización en el sur y levante de España hasta la época de Augusto», Blázquez, J.M.-Alvar, J. (eds.), La romanización de Occidente, Madrid, págs. 147-177.

KNAPP, R.C., (1977): Aspects of the Roman experience in Iberia 206-100 b.C., Valladolid.

Llorens, M. del M.; AquiluÉ, X. (2001): IlercavoniaDertosa $i$ les seves encunyacions monetàries, Barcelona.

López SÁnchez, F. (2005): «Moneda ibérica y hospitium», Actas del XIII Congreso Internacional de Numismática (Madrid, 2003), Madrid, 511-515.

LuJÁn, E.R. (2005): «Los topónimos en las inscripciones ibéricas», Acta Palaeohispanica $\mathrm{IX}=\mathrm{Pa}$ laeohispanica, 5, 471-490.

Mangas, J. (1996): Aldea y ciudad en la antigüedad hispana, Madrid.

Marques de Faria, A. (2000): «Crónica de onomástica paleo-hispânica (1)», Revista Portuguesa de Arqueología, 3.3, 61-66.

- (2001): «Crónica de onomástica paleo-hispânica», Revista Portuguesa de Arqueología, 4.1, 95107.

Martín, M. A.(1997): Ullastret. Guies del Museu d'Arqueologia de Catalunya, Girona.

Martín Bueno, M. (1993): «La ciudad hispanorromana en el valle del Ebro», La ciudad hispanorromana, Barcelona, 108-127.

Martín Valls, R. (1967): «La circulación monetaria ibérica», BSAA, XXXII, 207-366.

MatA, C. (2001): «Límites y fronteras en Edetania», $A P L$, XXIV, 243-272.

Mayer, M.; RodÀ, I. (1986): «La romanització de Catalunya. Algunes qüestions», Protohistoria Catalana. 6e. Col.loqui Internacional d'Arqueologia de Puigcerdà (1984), Puigcerdà, 339-351.

Mezquiriz, M.A. (1978): Pompaelo II, Pamplona.

NACO, T. (1999): «La presión fiscal romana durante las primeras décadas de la conquista de Hispania (218-171 a.C.): un modelo a debate», Studia Historica, Historia Antigua, 321-369.

ÑACO, T.; Prieto, A. (1999): «Moneda e historia monetaria en la Hispania republicana: ¿Economía, política, fiscalidad?», Studia Historica. Historia Antigua, 17, 193-241.

Olesti, O.; Mercadal, O., (2005): «La iberització del Pirineu Oriental i la filiació étnica dels ceretans», Acta Palaeohispanica IX= Palaeohispanica 5, 295-314.

Otiña, P.; Ruiz de Arbulo, J. (2000): «De Cese a Tárraco. Evidencias y reflexiones sobre la Tarragona ibérica y el proceso de romanización», Empuries, 52, 107-136.
Ozcáriz, P. (2006): Los conventus de la Hispania Citerior, Madrid, 2006.

Padró, J.; SAnMartí, E. (1992): «Áreas geográficas de las étnias prerromanas en Catalunya», Paleoetnología de la Península Ibérica, Complutum, 23, 185-194.

PAdrós, P. (2005): «Algunos ejemplos de la relación existente entre cecas ibéricas y fundaciones tardorepublicanas en el nordeste de la Hispania $\mathrm{C} i$ terior», Actas del XIII Congreso Internacional de Numismática (Madrid, 2003), Madrid, 523-530.

Pena, M.J. (1984): «Apuntes y observaciones sobre las primeras fundaciones romanas en Hispania», Estudios de la Antigüedad, 1, 47-85.

- (1989): «Avieno y las costas de Cataluña y Levante. I. Tyrichae: TYRIKAI ¿La Tiria?», Faventia, 11/2, 9-21.

Pera, J. (1994): «Reflexions entorn el municipium Sigarrensis», Actes Congrés Int. d'Arqueologia Clásica, Tarragona, 323-325.

- (1997): «Iesso i Sigarra en el marc de la romanització de la Citerior», RAP, 7, 229-236.

Perex, M.J. (1986): Los vascones. El poblamiento en época romana, Pamplona.

Pérez, A.; Soler, M. (1993): «Les seques d'Iltiŕda i Iltiraka i el llop ibèric», RAP, 3, 151-175.

Pérez Almoguera, A. (1993-1994): «Iltiŕta y Auso, dos capitales regionales en la Hispania republicana», AnMurcia 9-10, 193-208.

- (1994): «En torno a la ordenación del territorio y fundaciones romanas en el interior de Cataluña a fines del s. II e inicios del I a.C.», III Congreso Peninsular de Historia Antigua, Preactas II, Vitoria, 446-457.

- (1995): «Sobre la ceca de iltiŕkesken y su probable ubicación en el Bajo Ebro», Verdolay, 7, 321-325.

- (1996): «Las cecas catalanas y la organización territorial romano-republicana), AEspA. 69, 37-56.

- (1999): «Livio, 21, 61, 6-7: Atanagrum urbem, quae caput eius populi erat. El problema de Atanagrum y la capitalidad ilergete», HAnt, XXIII, $25-46$

- (2001-2002): «De nuevo sobre la ubicación de la ceca de Iltirke y el tritetartemorion de Sikarbi/ Sikara», AnMurcia 17-18, 253-262.

Pérez Vilatela, L. (1988): «La adscripción de Sagunto a sucesivas estructuras étnicas», Arse, 23, 9-17.

- (1991): «Ilercavones, celtíberos y cartagineses en 218-217 a.C.», Caesaraugusta, 68, 205-228.

Plácido, D. (1997): «Los iberos en los textos clásicos», Los iberos príncipes de occidente, Barcelona, 51-57. 
Pou, J.; Sanmartí, J.; Santacana, J. (1993): «El poblament ibéric a la Cessetania», Laietania, 8, 183206.

RAFEL, N. (1979): «Contribució a l'estudi de la circulació monetaria a la comarca del Penedés», Symposium Numismático de Barcelona, II, 15-20.

RAFEL, N. et al. (prensa): «La arqueología de la plata y su investigación en la Península Ibérica: el proyecto Plata romana en Catalunya», Congreso int. Mineria y Metalurgia. Pasado, presente y futuro (Mequinenza, 2006).

Richardson, J.S. (1986): Hispaniae. Spain and the Development of Roman Imperialism (218-82 B.C.), Cambridge.

RIPOLLÉs, P.P. (2005): «Las acuñaciones antiguas de la Península Ibérica: dependencias e innovaciones», Actas del XIII Congreso Internacional de Numismática (Madrid, 2003), Madrid, 187-205.

Rodríguez, P (1996): Gens. Una forma de agrupación mal conocida, Vitoria-Gasteiz.

Rodríguez NeILA, J.F. (1998): «Hispani principes. Algunas reflexiones sobre los grupos dirigentes de la Hispania prerromana», Cuadernos de Arqueología de la Universidad de Navarra, 6, 99-137.

Rodríguez Ramos, J. (2001-02): «Okelakom, Sekeida, Bolsken», Kalathos, 20-21, 429-434.

- (2005): «Los problemas del sufijo primario o temático -k en la lengua ibérica y del vocabulario de las inscripciones religiosas iberas», Faventia, 27/1, 23-38.

Roldán, J.M. (1983): «Antigüedad», en Historia de Granada, I, Granada.

Roldán, J.M.; SAntos, J. (1997): Historia de España II. Hispania romana. Conquista, sociedad y cultura (s. III a.C.-IV d.C.), Madrid.

Sanmartí, J.; Santacana, J. (2005): Els ibers del nord, Barcelona, 2005.

SAYAS, J.J. (1996): «Conquista y colonización del valle del Ebro en época tardorrepublicana y principado», Ortiz, E.-Dantos, J. (eds.), Revisiones de Historia Antigua II. Teoría y práctica del orde- namiento municipal en Hispania, Vitoria-Gasteiz, 63-82.

Siles, J. (1976): Sobre un posible préstamo griego en ibérico. SIP, Trabajos Varios 49, Valencia.

TARradell, N. (2003/2004): «Les monedes del Castellet de Banyoles de Tivissa (Ribera d’Ebre, Catalunya). Noves troballes de les excavaciones 1998-1999 i revisió de les anteriors», Fonaments 10/11, 245-317.

TIR K/J 31 (1997): Tabvla Imperii Romani, Tarraco, Baliares, Madrid.

Tovar, A. (1989): Iberische Landeskunde. 3 Tarraconensis, Baden-Baden.

Untermann, J. (1975): Monumenta Linguarum Hispanicarum, 1, Wiesbaden.

- (1992): «los etnónimos de la Hispania antigua y las lenguas prerromanas de la Península Ibérica», Complutum, 2-3, 19-33.

VelazA, J. (1995): «Epigrafía y dominios lingüísticos en territorio de los vascones», en Beltrán, F. (ed.), Roma y el nacimiento de la cultura epigráfica en Occidente, Zaragoza, 209-218.

Villaronga, L. (1961): «El hallazgo de Balsareny», Numario Hispánico, X, 9-102.

- (1979): Numismática antigua de Hispania, Barcelona.

- (1982): «Les seques ibèriques catalanes: una sintesi», Fonaments, 3, 135-183.

- (1983): Les monedes ibèriques de Tarraco, Tarragona.

- (1994a): Corpus Nummum Hispaniae ante Augusti Aetatem, Madrid.

- (1994b): «Antiguitat», en Benages, J., Les monedes de Tarragona, 18-36, Tarragona.

- (1998), Les dracmes ibèriques i llurs divisors, Barcelona.

- (2004), Numismática antiga de la Península Ibérica, Barcelona.

Recibido el 21-06-07. Aceptado el 11-03-08. 